\title{
Towards a real-time susceptibility assessment of rainfall-induced shallow landslides on a regional scale
}

\author{
L. Montrasio, R. Valentino, and G. L. Losi \\ Department of Civil, Environmental, Territory Engineering and Architecture, University of Parma, Viale G. P. Usberti 181/A \\ 43100 Parma, Italy
}

Received: 13 October 2010 - Revised: 31 March 2011 - Accepted: 2 May 2011 - Published: 12 July 2011

\begin{abstract}
In the framework of landslide risk management, it appears relevant to assess, both in space and in time, the triggering of rainfall-induced shallow landslides, in order to prevent damages due to these kind of disasters. In this context, the use of real-time landslide early warning systems has been attracting more and more attention from the scientific community. This paper deals with the application, on a regional scale, of two physically-based stability models: SLIP (Shallow Landslides Instability Prediction) and TRIGRS (Transient Rainfall Infiltration and Grid-based Regional Slope-stability analysis). A back analysis of some recent case-histories of soil slips which occurred in the territory of the central Emilian Apennine, Emilia Romagna Region (Northern Italy) is carried out and the main results are shown. The study area is described from geological and climatic viewpoints. The acquisition of geospatial information regarding the topography, the soil properties and the local landslide inventory is also explained.

The paper outlines the main features of the SLIP model and the basic assumptions of TRIGRS. Particular attention is devoted to the discussion of the input data, which have been stored and managed through a Geographic Information System (GIS) platform. Results of the SLIP model on a regional scale, over a one year time interval, are finally presented. The results predicted by the SLIP model are analysed both in terms of safety factor $\left(F_{\mathrm{S}}\right)$ maps, corresponding to particular rainfall events, and in terms of time-varying percentage of unstable areas over the considered time interval. The paper compares observed landslide localizations with those predicted by the SLIP model. A further quantitative comparison between SLIP and TRIGRS, both applied to the
\end{abstract}

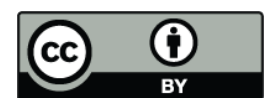

Correspondence to: R. Valentino (roberto.valentino@unipr.it) most important event occurred during the analysed period, is presented. The limits of the SLIP model, mainly due to some restrictions of simplifying the physically based relationships, are analysed in detail. Although an improvement, in terms of spatial accuracy, is needed, thanks to the fast calculation and the satisfactory temporal prediction of landslides, the SLIP model applied on the study area shows certain potential as a landslides forecasting tool on a regional scale.

\section{Introduction}

Rainfall-induced shallow landslides, also called "soil slips" (Cruden and Varnes, 1996), are usually triggered by short duration and intense rainfalls or, alternatively, by prolonged light rainfalls. They have been widely described by many authors, referring to historical events which prevalently occurred in temperate regions (Kesseli, 1943; Campbell, 1974, 1975; Moser and Hohensinn, 1983; Ellen and Fleming, 1987; Sassa, 1998; Crosta et al., 2003; Schmidt et al., 2008; Zezere et al., 2008). Soil slips generally involve small portions of shallow soils and are characterised by a high density distribution over wide areas.

At the moment, in regional and urban planning, hazard and susceptibility maps regarding this special kind of landslides are frequently used. Such maps usually indicate the possible location of landslides on the basis of data regarding the events occurring in the past (Santacana et al., 2003). Many authors have applied statistical correlations, which are based on the knowledge of previous events and take into account, beside rainfalls, other important variables which can influence landslides, such as geology, geometry, groundwater and geotechnical characteristics of the soil (Carrara et al., 1991; Bai et al., 2009; Cervi et al., 2010). 
On the other hand, real-time early warning systems, which are attracting the attention of the scientific community, are being used more and more as a tool in territory administration, since they allow a "dynamic" (time varying) monitoring on a regional scale and environmental management. It is clear that these innovative systems require coupling between rainfall amounts, hydrological models and slopestability analyses.

Most of the early warning systems, which are used, for the time being, as prototypes, are based on rainfall-triggering thresholds (Wilson and Wieczorek, 1995; Crosta, 1998; Borga et al., 2002; Crosta and Frattini, 2003; Aleotti, 2004; Guzzetti et al., 2007, 2008; Tiranti and Rabuffetti, 2010; Capparelli and Versace, 2011; Capparelli and Tiranti, 2010).

Since shallow landslides always occur as a result of rainfall infiltration, for many authors it is reasonable to evaluate this type of slope instability using physically based models to simulate the transient hydrological and geotechnical processes involved (Montgomery and Dietrich, 1994; Wu and Sidle, 1995; Terlien, 1998; Iverson, 2000; Qiu et al., 2007; Baum et al., 2008; Lu and Godt, 2008; Baum and Godt, 2010). The formulation of such models, together with the wide availability of GIS, has led to the development of methods that appear suitable in determining both the time and the localization of soil slips, in response to rainfall, on a regional scale (Borga et al., 1998; Burton and Bathurst, 1998; Iiritano et al., 1998; Iovine et al., 2003; Aleotti, 2004; Salciarini et al., 2006, 2008; Godt et al., 2008a, b; Schmidt et al., 2008; Simoni et al., 2008; Apip et al., 2010; Vieira et al., 2010; Liao et al., 2010a, b). These methods are characterised by different levels of complexity and their quality is strictly correlated with the quality of input data.

The simplified SLIP (Shallow Landslides Instability Prediction) model, which is applied in the present work, falls within this context (Montrasio, 2000) and has been applied in the analysis of many case histories on a local scale (Montrasio and Valentino, 2007, 2008; Montrasio et al., 2009). Dynamically, this model takes into account the stability condition of a slope, the characteristics of the soil and the rainfall amounts, including previous rainfalls.

After implementation on a platform using GIS data, the SLIP model has been applied to different areas on a regional scale. This paper mainly deals with the back analysis of some recent case-histories occurring in 2005 in the central Emilian Apennine, Emilia Romagna Region (Northern Italy) (Fig. 1). The study area is firstly described from geological and climatic points of view. The main assumptions of the SLIP model are explained and particular attention is devoted to the discussion of the input data, which have been introduced through a GIS framework. The input data include slope geometric features, the geotechnical characteristics of involved soils, the drainage capability of the slope, the rainfall infiltration mechanism and time varying rainfalls. The results of the slope-stability analysis, carried out over a one year time span, are finally presented.
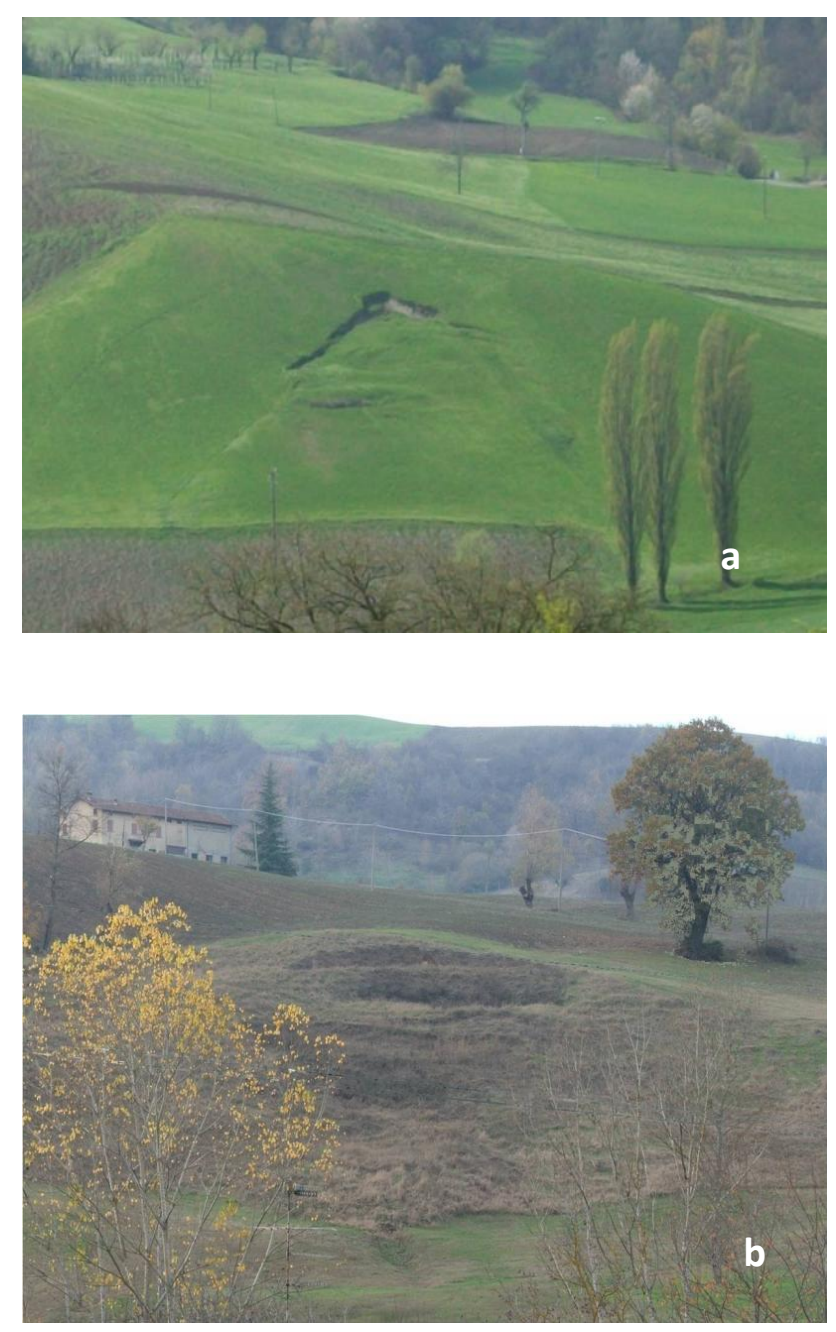

Fig. 1. Some examples of soil slips occurred in the Emilian Apennine in April 2005: (a) Regnano and (b) Brugna.

In order to obtain a quantitative comparison of the presented model, TRIGRS (Baum et al., 2008) has been chosen as a well-established process-based reference method. The stability analyses have been carried out using the SLIP and the TRIGRS models for the most important event which occurred during the analysed period. The main peculiarities distinguishing the two models are outlined and their predictive capabilities are finally evaluated using the ROC plot quantitative method.

\section{The study area}

The area under study, which is located in the Emilia Romagna Region (Northern Italy), extends from the Middle Apennine, in the Southern part, to the Po River plain, in the northern part. The altitudes range between $130 \mathrm{~m}$ a.s.l. in the north-eastern portion and $936 \mathrm{~m}$ a.s.l. of Mount Valestra in 


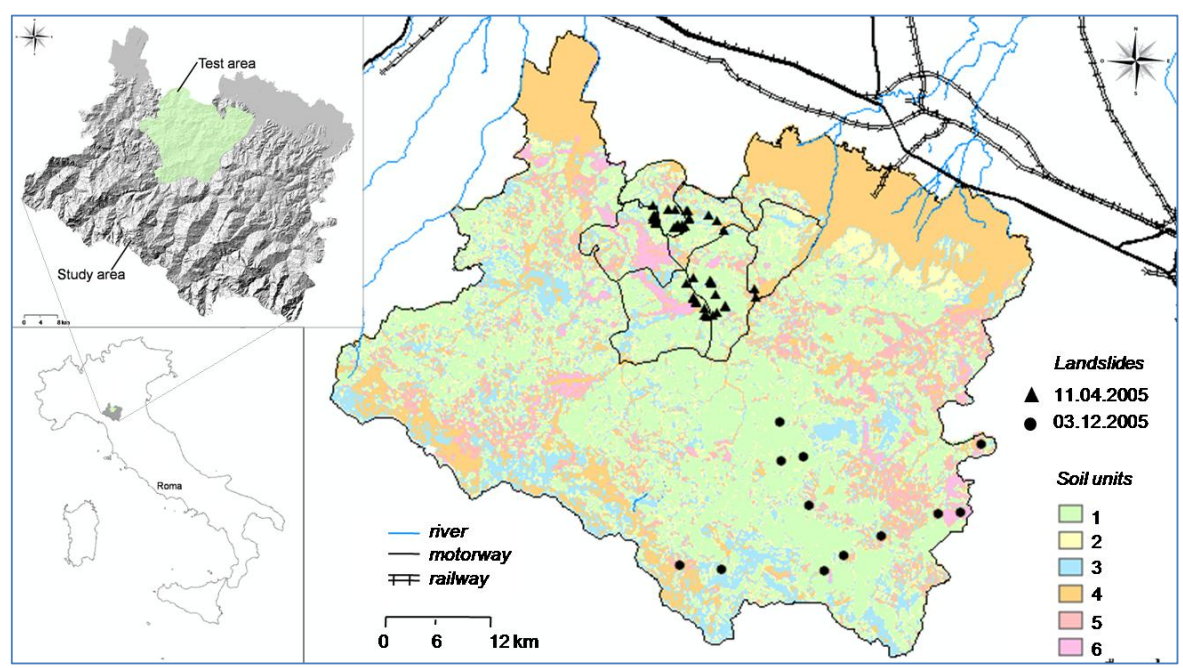

Fig. 2. Study area and test-area with soil units. Localization of soil slips occurring on the 11 April and 3 December 2005.

the southern portion. Figure 2 shows the geographical location of the study area.

The slope stability analyses, described in the following, have been carried out at two main levels: (i) considering only a small portion of the study area (called "test-area"), where many shallow landslides occurred during an intense rainfall event in April 2005, and (ii) taking into account the entire study area (Fig. 2). The test-area corresponds to the municipalities of Vezzano sul Crostolo, Viano, Baiso, Carpineti, Casina and Castellarano and extends over $370 \mathrm{~km}^{2}$. The wider study area, which includes the test-area, extends over $1200 \mathrm{~km}^{2}$.

\subsection{Climatic conditions}

The climate in the study area is mainly of the ApennineMediterranean type, characterised by an average annual rainfall between $1000 \mathrm{~mm}$ (in the highest areas) and $800 \mathrm{~mm}$ (at the foothills), with two annual maxima - one in autumn (November) and the other in late spring (April-May) - spaced out by two minima - a more pronounced one in summer (July) and the other in winter (January). The average annual isotherms follow the altitude trend and range from $9.5^{\circ} \mathrm{C}$ to about $12.5^{\circ} \mathrm{C}$. The average daily temperatures are highest in July and lowest in January.

The climatic conditions immediately preceding the triggering of many shallow landslides, which occurred in April 2005, were significantly different from the average conditions of previous years. By analysing the data from the Baiso thermo-pluviometric station (542 m a.s.l.), which can be considered the main representative station of the testarea, the month of April 2005 was characterised by an exceptional rainfall of $141.2 \mathrm{~mm}$ with as much as $99.8 \mathrm{~mm}$ of rainfall in just $60 \mathrm{~h}$, of which $58.8 \mathrm{~mm}$ in the first $24 \mathrm{~h}$ on the 10 April 2005 (Fig. 3). The monthly precipitation in March

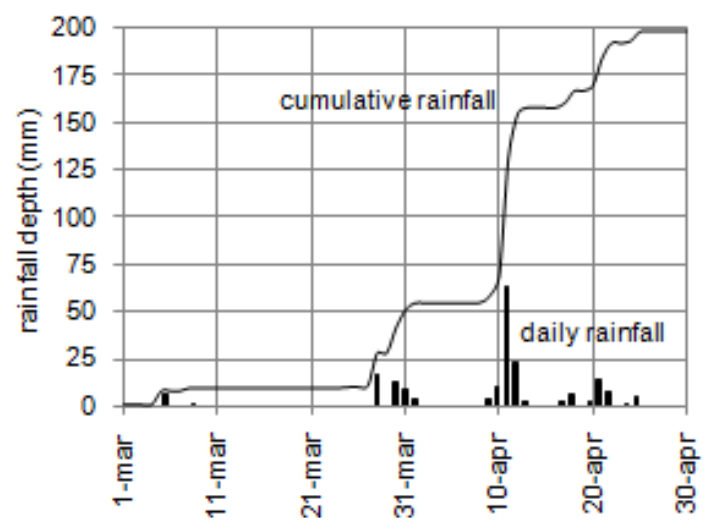

Fig. 3. Daily and cumulative rainfalls measured from 1 March to 30 April 2005 at Baiso rain gauge.

of the same year was almost one third of the precipitation observed in April. The period between the end of February and the beginning of March 2005 was characterised by frequent weak snow precipitations, with temperatures constantly below $0{ }^{\circ} \mathrm{C}$. Although the solid component of the precipitation should be taken into account, it is difficult, due to the lack of instruments for measuring the liquid equivalent of snow precipitation. For this reason, the solid precipitation is disregarded in the stability analysis.

\subsection{Geological characteristics}

The Northern Italian Apennine is formed by the tectonic overlap of two major units: Tuscan Domain and UmbroMarchigiano-Romagnola Succession (Castronuovo, 2005).

In the Emilian Apennine fringes, these successions are composed of marine and continental deposits, which, in relation to the Po River plain, exhibit a regressive character. 
The marine deposits, from the higher Miocene period to the Pleistocene period, represent the recent filling of the partially deformed Apennine front graben, while the continental deposits represent the latest evolution of the considered area (Pieri and Groppi, 1981).

The Emilian Apennine fringes oriented towards NW-SE can be divided into two sections: the high and the middle-low Apennine, respectively. The study area concerns predominantly the middle-low Apennine, where Ligurian and Epiliguri units crop out, and is characterised by a structure with overlapping layers deposited from the lower-middle Miocene period to Plio-Pleistocene period.

The soils of oligo-miocenica Epiligure succession are mainly characterised by little deformations. They are usually folded into mild syncline (syncline of Vetto-Carpineti and Viano) or are sub-horizontal or gently deeping monocline. These structures are affected by a tectonic disjunction with direct or sub-vertical faults oriented in different directions with limited throw. Even the plio-Pleistocene deposits, cropping out on the hills on the fringes of the plain, are characterised by limited deformations. Normally, they constitute monocline emerging towards North, cut by small direct or vertical faults. In the northernmost outcrop the layers tend to become vertical causing a flexure (also denoted as Lineamento Frontale Pedappenninico), connected to the system of Emilian folds which have the largest development in the subsoil of the plain (Castronuovo, 2005).

In the past, widespread mass movements of different types occurred in this area. Most of these movements had typical characteristics of soil slips, involving shallow soil layers consisting of quaternary detritus. Field surveys revealed that the soil profile was nearly the same in all landslide sites.

The soil profiles can be divided into three main layers:

1. the colluvium layer extends to the depth of $1.2 \mathrm{~m}$ from the ground level and is composed of weathered bedrock and material derived from down-slope transportation. This layer is made of mostly silty or silty-clay deposits, with a small percentage of sand, and sometimes contain coarse calcareous fragments smaller than $10 \mathrm{~mm}$. Similarly to other quaternary deposits of Northern Italian Apennine (Meisina, 2004), this layer has been significantly disturbed by the swelling-shrinking phenomena, with fissures and slicken-sides frequently showing signs of past desiccation. During the dry season, the width of some cracks on the slope surface reaches up to 20$30 \mathrm{~mm}$ and extends down to $0.8-1 \mathrm{~m}$ from ground level;

2. the transition zone, is composed of partially weathered bedrock, and is characterised by a thickness ranging from $0.3 \mathrm{~m}$ up to $0.6 \mathrm{~m}$;

3. the subsoil or unweathered bedrock appears more uniform than the upper layers and is less disturbed by the swelling-shrinking phenomena. The thickness of this layer can reach several metres and consists of a high percentage of clay with marly fragments. This deep layer exhibits relatively low hydraulic conductivity.

\section{Shallow landslides occurred during 2005 in the Emilian Apennine}

The localization of shallow landslides which occurred on the 10-11 April 2005 (Fig. 2) was obtained from the study of aerial photographs. The aerial photographs were taken in the spring of 2004 by the Technical Service for the Secchia and Panaro Basins (Reggio Emilia) on a 1:12000 scale. Subsequently, an inventory of the surface phenomena occurring after the snow melt in April 2004 was created and was later integrated with validation visits carried out in April 2005 (Cervi et al., 2010). Through the comparison between the aerial photographs of 2004 and the field surveys conducted in 2005, it was possible to map about 70 landslides caused by the only rainfall event of April 2005 (Castronuovo, 2005; Cervi et al., 2010). Only 45 of these landslides, which can be classified as soil slips, have been considered in this study and are mapped in Fig. 2. Given their limited average extension (from a few tens to a few hundreds of square metres) and the scale ratio used (1:25000), these landslides have been mapped as points in Fig. 2.

During December 2005, another rainfall event led to the triggering of a certain number of soil slips in the southeastern part of the study area at a distance of several kilometres from the landslides which occurred in April 2005 (Fig. 2). From the landslide inventory of Regione Emilia Romagna, we had at our disposal the reports of a dozen soil slips which occurred on the 3 December 2005.

After the analysis of the inventory maps of these two events, it was decided to extend the study area. In fact, the 45 landslides which occurred on the 11 April 2005 appear rather concentrated (Fig. 2) in a small part of the considered area (nearly $370 \mathrm{~km}^{2}$ ), which has been assumed as a "testarea". In the following, the stability analysis has been carried out both on the "test-area" and on the entire study area (nearly $1200 \mathrm{~km}^{2}$ ). In this study, the first event of April 2005 was used as a reference event for the model calibration and the second event, which occurred in December 2005, was used to verify the predictive capability of the model while keeping the input parameters constant. For both events, most of the slides involved only shallow soil layers of the quaternary silty or clayey silt deposits, with thicknesses varying from $1.0 \mathrm{~m}$ to $1.5 \mathrm{~m}$ on slopes ranging between $10^{\circ}$ and $30^{\circ}$ and prevalently dedicated to agricultural use. Field surveys revealed that the failure surface was located in correspondence to a change in hydraulic conductivity, i.e., where the base layer, which could be either the transition zone or the unweathered bedrock, was less permeable than the upper one, at a depth between $1.0 \mathrm{~m}$ and $1.5 \mathrm{~m}$ from ground level. In fact, the colluvium is characterised by a relatively high 


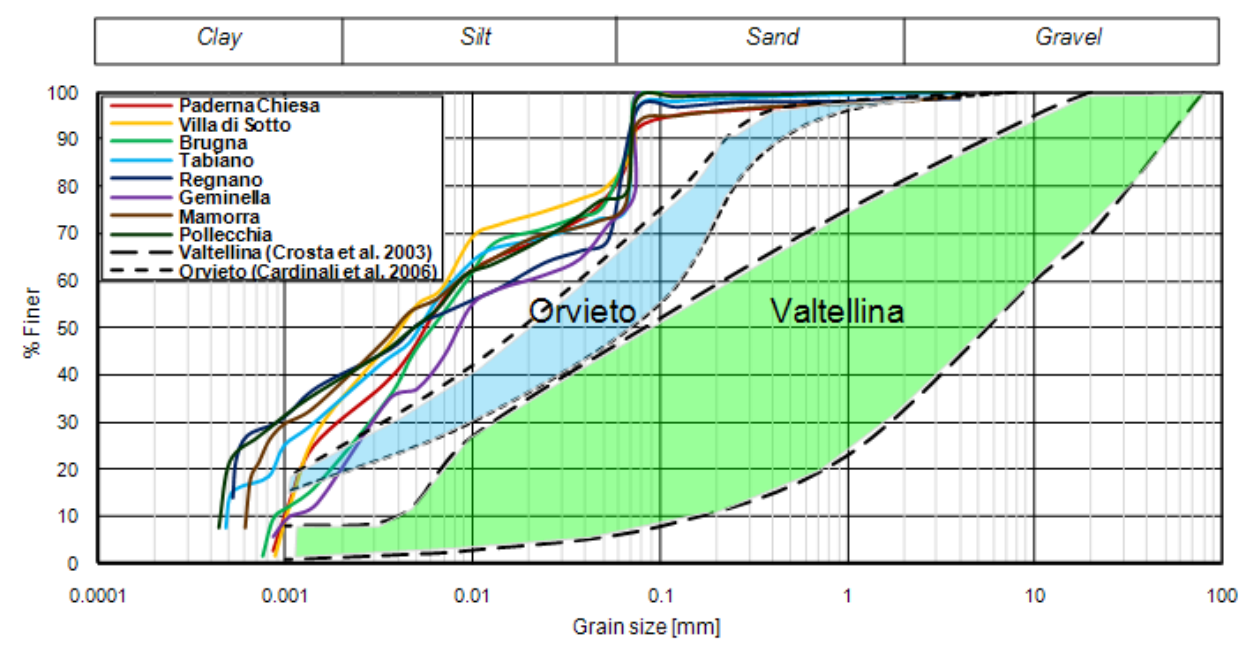

Fig. 4. Grain size distribution curves of shallow soils involved in soil slips in 8 sample sites of the test-area, compared with those of other Authors.

permeability, due to fissures, gaps and channels, which tend to close with depth and obstruct the rapid transport of surface water to groundwater.

The geotechnical characterisation of colluvial deposits involved in soil slips was based on standard laboratory analyses, conducted according to the ASTM methods. The performed tests include (i) determination of the physical parameters of materials (grain size distribution, bulk and dry densities, Atterberg limits, porosity, natural water content, degree of saturation) and (ii) standard drained triaxial tests.

The colluvial soils collected in 8 different sites of the testarea are classified as clayey silt (the percentage of clay is less than 30 percent) (Fig. 4) based on grain-size distribution. According to the USCS classification, the majority of the analysed samples have medium-high plasticity (MH) (Fig. 5). The studied soils appear quite different from those involved in soil slips in other Italian sites (Crosta et al., 2003; Cardinali et al., 2006) (Fig. 4). The grain density ranges between $25 \mathrm{kN} \mathrm{m}^{-3}$ and $27 \mathrm{kN} \mathrm{m}^{-3}$. The soil porosity ranges between 0.42 and 0.50 . The shear strength parameters from triaxial tests are represented by a friction angle of $24^{\circ}-25^{\circ}$ and an effective cohesion of $0-5 \mathrm{kPa}$.

From a geotechnical viewpoint, the soil profiles present only slight differences. In most cases, from the sandy-silty surface layers to the deeper clayey silty layers, there is a decrease with depth of the soil grain size. The colluvial deposits have medium-high permeability which decreases with depth.

\section{Physically-based models for regional slope-stability analysis}

The slope-stability analysis, on a regional scale, for the sites affected by the shallow landslides described in the previous section, has been carried out using two physically based models: the SLIP model, which has been recently developed by the authors (Montrasio, 2000; Montrasio and Valentino, 2008) and the TRIGRS model (Baum et al., 2008), a wellestablished process-based method which has been assumed as a reference model for quantitative comparison with SLIP's results. In this section, the basic assumptions and the main peculiarities distinguishing these two models are outlined.

Both models assume the hypothesis of infinite slope. This assumption is rather common when determining the stability condition in the presence of shallow and translational soil slips with a maximum depth of approximately $1.5-2 \mathrm{~m}$ (Godt et al., 2008a). In particular, field surveys in the test area have shown that in most cases the shallow, unstable layer was rather thin with respect to the superficial extent of the scars: for this reason, the infinite slope model can be considered appropriate.

Another hypothesis that is common to both models concerns the influence of topography on the subsurface flow, which leads to the disregard of the spatial transient nature of the hydrological processes before and during the triggering mechanism of shallow landslides. Some authors (Iverson, 2000; Godt et al., 2008a) have stated that areas of the landscape where the vertical component of pore-pressure response to rainfall dominates over lateral transmission can be easily identified, after defining $H$ as the depth of the failure surface in the slope-normal direction, and $A_{\mathrm{c}}$ as the upslope contributing area above a given location. By considering the ratio $\varepsilon=H / A_{\mathrm{c}}^{0.5}$, it can be assumed that, for areas where $\varepsilon \ll 1$, long- and short-term pressure-head responses to rainfall are prevalently dominated by vertical flow. These areas are typical of shallow landslide locations (Iverson, 2000). This implies that pore-pressure variation, in response to rainfall in initially wet materials, can be adequately described by simplified, one-dimensional hydrologic models. 


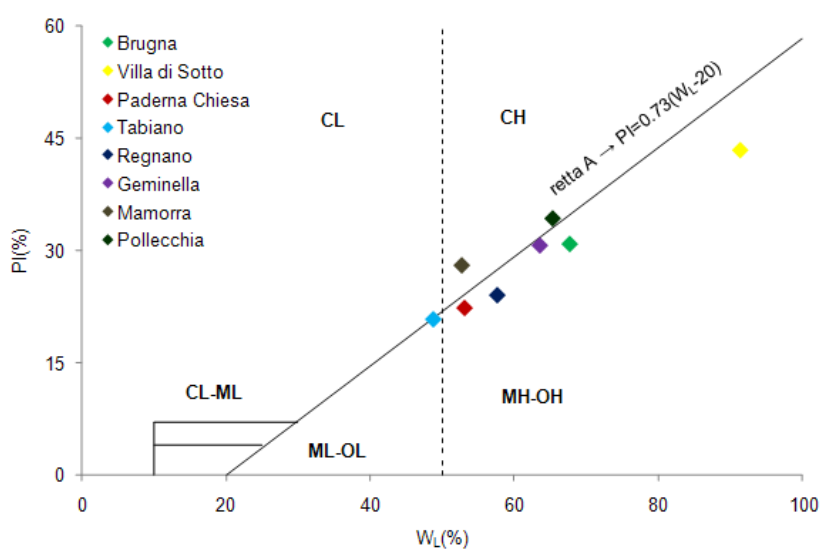

Fig. 5. Plasticity chart for classification of shallow soils involved in soil slips in the test-area.

The assumption of diverse hydrologic models is the main difference between SLIP and TRIGRS, which will be explained in the following section.

\subsection{SLIP}

The slope stability is evaluated through the definition of the safety factor $F_{\mathrm{s}}$, calculated using the limit equilibrium method. Stabilizing forces are evaluated on the basis of the Mohr-Coulomb strength criterion, including the contribution to the soil strength given by the partial saturation, in terms of apparent cohesion of the soil, which plays a key role in the triggering mechanism.

The safety factor, considering the soil slice shown in Fig. 6, can be defined as follows:

$F_{\mathrm{s}}=\frac{\cot \beta \cdot \tan \phi^{\prime} \cdot\left[\Gamma+m \cdot\left(n_{\mathrm{w}}-1\right)\right]+C^{\prime} \cdot \Omega}{\Gamma+m \cdot n_{\mathrm{w}}}$

where:

$\Gamma=G_{\mathrm{s}} \cdot(1-n)+n \cdot S_{\mathrm{r}}$

$n_{\mathrm{w}}=n \cdot\left(1-S_{\mathrm{r}}\right)$

$\Omega=\frac{2}{\sin 2 \beta \cdot H \cdot \gamma_{\mathrm{w}}}$

$C^{\prime}=\left[c^{\prime}+c_{\psi}\right] L=\left[c^{\prime}+A \cdot S_{\mathrm{r}} \cdot\left(1-S_{\mathrm{r}}\right)^{\lambda} \cdot(1-m)^{\alpha}\right] L$

The symbols in Eqs. (1-5) have the following meanings:

$\beta$ is the inclination of the potentially unstable slope;

$\phi^{\prime}$ is the soil shear strength angle;

$\gamma_{\mathrm{w}}$ is the water weight per unit volume;

$H$ is the thickness of the potentially unstable layer;

$L$ is the length of the soil slice;

$m$ represents the saturated fraction of the soil layer with respect to its thickness $\left(m=H_{\text {sat }} / H\right)$;

$n$ is the porosity of the soil;

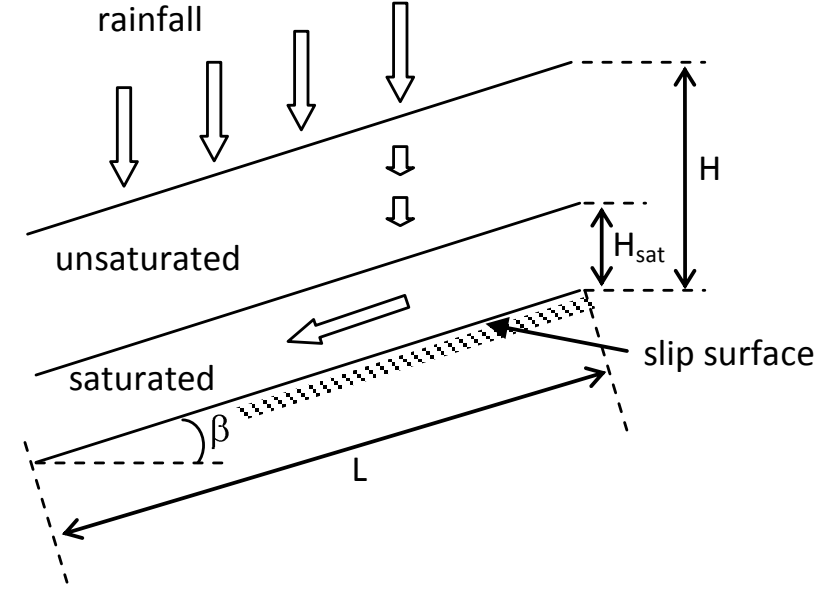

Fig. 6. Sketch of an infinite slope and scheme of the infiltration model. ( $\beta$ is the inclination of the potentially unstable slope; $H$ is the thickness of the potentially unstable layer; $L$ is the length of the soil slice).

$G_{\mathrm{S}}$ is the specific weight of the soil;

$S_{\mathrm{r}}$ is the degree of saturation of the soil;

$c^{\prime}$ is the effective cohesion of the soil;

$c_{\psi}$ is the apparent cohesion given by the partial saturation of the soil;

$A, \lambda$, and $\alpha$ are numerical parameters.

In Eq. (5) the apparent cohesion $\left(c_{\psi}\right)$ is expressed as a function of the degree of saturation of the soil on the basis of experimental results (Fredlund et al., 1996), after the introduction of parameters $A$ and $\lambda$, which depend on the soil type (Montrasio and Valentino, 2008). Moreover, it is clear that during prolonged rainfalls, the degree of saturation increases, and the shear strength contribution given by the partial saturation is lost in most of the soil. Parameter $m$ is defined as the ratio between the saturated soil thickness $\left(H_{\text {sat }}\right)$ and the potentially unstable thickness $\left(m=H_{\text {sat }} / H\right)$. Equation (5) takes into account that, during prolonged rainfalls, the apparent cohesion $\left(c_{\psi}\right)$ decreases due to the formation of a relatively wide continuous stratum of saturated soil while $m$ increases until provoking instability. A supplementary parameter, namely $\alpha$, is introduced in Eq. (5) to express the shear strength along the failure surface in terms of $m$. The quantity (1- $m$ ) corresponds to the soil normalized thickness that remains in a condition of partial saturation during rainfall. The parameter $\alpha$ assumes the value of 3.4 according to experimental tests (Montrasio and Valentino, 2007).

\subsubsection{Correlation between safety factor and rainfalls}

Given the characteristics of the previously described colluvium, the rain water flows easily through the macropores and reaches the deeper parts of the many natural micro-channels and fissures. On account of the hydraulic 
heterogeneity of the shallow soil, it is rather difficult to suppose a uniform surface infiltration and the formation of a continuous tension-saturated zone. Instead, it is more realistic to assume that the water flows from macro-pores to micro-pores in different directions. This infiltration, in turn, causes the saturation of non-adjacent volumes of the shallow soil (dualporosity effect) (Zhang and Zhang, 2009). The process continues whilst the rainfall persists, and larger and larger portions of soil become saturated, until the saturated soil layer reaches a thickness equal to $H_{\text {sat }}$ starting from the impermeable front. At the same time, in the saturated zone, a 1-D downslope steady seepage occurs governed by macro- and micro-porosity of the soil (Zhang and Zhang, 2009). In the stability analysis (Eq. 1), this is taken into account through the downslope destabilizing seepage force (Montrasio and Valentino, 2008).

In order to simplify the modeling of this complex mechanism and to obtain the direct correlation between safety factor $\left(F_{\mathrm{s}}\right)$ and rainfall depth $(h)$, the above-mentioned $m$ ratio is introduced. We suppose that $m$ can be expressed through a function of rainfall depth $(h)$ :

$m=m(h)$

Since $h$ depends on time, Eq. (6) is also indirectly dependent on time $(t)$. Parameter $m$, in fact, can be constant or variable in time and is correlated to the volume of water $V_{\mathrm{w}}$ required to saturate a soil slice, which is initially characterised by a degree of saturation $S_{\mathrm{r}}<1$. Considering the saturated part of the soil slice (Fig. 6), with a slope $\beta$, thickness $H_{\text {sat }}$, horizontal length $\Delta s=\mathrm{L} \cos \beta$ and unit width (1) (see Fig. 6), the water volume $V_{\mathrm{w}}$ that saturates the soil is given by:

$V_{\mathrm{W}}=m \cdot H \cdot n \cdot\left(1-S_{\mathrm{r}}\right) \cdot \Delta s \cdot 1$

so it is possible to obtain the relationship between parameter $m$ and the volume of water related to $\Delta s \cdot 1$ sized surface $\left(V_{\mathrm{w}}\right)$.

$m=\frac{V_{\mathrm{w}}}{n \cdot H \cdot\left(1-S_{\mathrm{r}}\right) \cdot \Delta s \cdot 1}$

The ratio $\frac{V_{\mathrm{w}}}{\Delta s \cdot 1}$ that appears in Eq. (8) corresponds to the water depth $H_{\mathrm{w}}$, which can saturate the lower part of the slice. $H_{\mathrm{w}}$, in turn, can be considered equal to a portion of rainfall depth $(h)$, because it has been assumed that an increment of water depth $\Delta H_{\mathrm{w}}$, caused by a rainfall, crosses the upper unsaturated part of the layer (Fig. 6) without modifying its degree of saturation, instantaneously reaching the impermeable layer and provoking an increment of $m(\Delta m)$. On the other hand, our interest is to evaluate the increment of $m$ after a rainfall event that can be described in terms of rainfall depth $(h)$. Equation (8) then becomes as follows:

$m=\frac{\xi \cdot h}{n \cdot H \cdot\left(1-S_{\mathrm{r}}\right)}$ where $\xi \cdot h$ is the contribution to the increment of $m$ given by rainfall, i.e., the infiltrated rainfall, and $\xi$ is a runoff coefficient. It has been considered, in fact, that the total rainfall amount does not completely infiltrate the soil. It is well known that runoff depends strongly on the existing soil moisture at the time of the rainfall event, because in dryer conditions a higher amount of soil storage volume is available to be filled before runoff (Pistocchi et al., 2008). But it is also true that for the kind of soil considered in this study a constant value of runoff coefficient can be determined (Pistocchi et al., 2008). On the basis of these considerations, it has been assumed that only a portion of the rainfall depth works in raising $m$ in the soil. This portion of rainfall is expressed by the coefficient $\xi$, which can be reasonably considered as a constant calibration coefficient for a certain soil and in the same conditions. In turn, the portion of runoff that can form an overland flow, is disregarded in this analysis, since its effect can be considered small in respect to the infiltrated rainfall.

If $m$ is calculated by considering a time interval equal to one day, then $h$ is the daily cumulated rainfall depth. But the most interesting aspect, for a direct correlation between $m$ and rainfall, consists in obtaining a dynamic evaluation of $m$ as a function of time over a period much longer than one day.

Moreover, it can be considered that the quota of $m$, given by the rainfall depth $(h)$, decreases in time as a consequence of such causes as a natural drying process, evapotranspiration, downward leakage and percolation. As stated by Saxton and Lenz (1967), the longer the time lapse between a rainfall event and a given day, the less influence the rain has on the soil moisture content of that day. This reduction of influence can be expressed as a modification of the Antecedent Precipitation Index (API) model (Saxton and Lenz, 1967) through a decreasing exponential relation, in which the exponent is represented by a numerical parameter. Therefore, by considering Eq. (9) and by expressing explicitly the dependence on the time $(t), m(h)$ can be written as follows:

$m(h)=\frac{\xi \cdot h}{n H\left(1-S_{\mathrm{r}}\right)} \cdot \exp \left[-K_{T}\left(t-t_{0}\right)\right]$

In Eq. (10) the numerical coefficient $K_{T}$ assumes the meaning of a drainage capability (its dimension is the inverse of time, i.e., in this case $\mathrm{d}^{-1}$ ) and $t_{0}$ is the starting time interval, i.e., the first day of computation. It is expected that $K_{T}$ should depend on the type of soil as a function of the soil permeability, since a higher hydraulic conductivity allows a faster decrease of accumulated water. On the other hand, one should observe that the rainfall infiltration mechanism is deeply affected by macro-porosity, which may have an opposite effect with respect to the saturated soil permeability.

On the basis of the above derivation, $m$ can be defined as a function of time correlated to the amount of rainfall $(h)$ within the time interval $\left(t-t_{0}\right)$ (in days).

If instead of representing an instantaneous (or daily) variation of $m$, one wants to obtain a dynamic trend, considering 
that the variation of $m$ at each time interval depends on previous rainfalls, the function $m(h)$ could be rewritten as the sum of a set of terms corresponding to different time intervals $\left(t-t_{i}\right)$. In other words, the expression of $m(h)$ can be discretized and expressed as a sum of terms including the rainfall depth $h_{i}$ over the $\omega$ previous time intervals, which correspond to the prior days. To summarize, under the assumption that porosity and the fabric of the soil remain constant over time, Eq. (5) can be rewritten as follows:

$m=\frac{\xi}{n H\left(1-S_{\mathrm{r}}\right)} \cdot \sum_{i=1}^{\omega} h_{i} \cdot \exp \left[-K_{T}\left(t-t_{i}\right)\right]$

Although it has been obtained empirically, Eq. (11) allows a fast and simple evaluation of the saturated portion of a shallow soil as a function of the rainfall depth during time. A detailed description of the model is presented in Montrasio and Valentino (2008).

\subsection{TRIGRS}

The Transient Rainfall Infiltration and Grid-Based Regional Slope-Stability (TRIGRS) model is a Fortran programme designed for modelling the timing and distribution of shallow, rainfall-induced landslides (Baum et al., 2008). Only a short description is reported here, since many authors used and described in detail this model in the past decade (Baum et al., 2008; Godt et al., 2008a, b; Salciarini et al., 2008; Kim et al., 2010; Liao et al., 2010b). The TRIGRS model is based on the method proposed by Iverson (2000), by taking into account complex rainfall histories, an impermeable basal boundary at finite depth, and a simple runoff routing scheme. The programme computes transient pore-pressure changes, and changes in the factor of safety, due to rainfall infiltration. It models rainfall infiltration, resulting from storms that have durations ranging from a few hours to a few days, by analytically solving partial differential equations that represent onedimensional vertical flows in isotropic and homogeneous materials, for either saturated or unsaturated conditions. Use of step-function series allows the programme to represent a variable rainfall input, and a simple runoff routing model diverts excess water from impervious areas onto more permeable downslope areas.

The TRIGRS programme uses a simple infinite-slope model to compute the factor of safety on a cell-by-cell basis. The factor of safety, denoted as $F_{\mathrm{s}}$, can be expressed, for transient pressure heads at multiple depths $Z$, as follows:

$F_{\mathrm{s}}=\frac{\tan \varphi^{\prime}}{\tan \beta}+\frac{c^{\prime}-\psi(Z, t) \gamma_{\mathrm{w}} \tan \varphi^{\prime}}{\gamma_{\mathrm{s}} Z \sin \beta \cos \beta}$

where $c^{\prime}$ is the soil effective cohesion, $\phi^{\prime}$ is the soil shear strength angle, $\psi$ is the ground-water pressure head as a function of depth $Z$ and time $t, \beta$ is the slope angle, and $\gamma_{\mathrm{w}}$ and $\gamma_{\mathrm{s}}$ are the unit weights of water and soil, respectively.

The depth $Z$ where $F_{\mathrm{s}}$ first becomes equal to 1 corresponds to the depth of landslide initiation. This initiation depth depends on the soil properties and on the time and depth variation of the pressure head, which, in turn, depends on the rainfall history. The use of an approximate expression for the effective stress in unsaturated materials can ease the computation of the factor of safety in unsaturated soils. Horizontal heterogeneity is accounted for by allowing material properties, rainfall and other input values to vary from cell to cell.

\subsection{Peculiarities of SLIP and TRIGRS}

The main difference between SLIP and TRIGRS consists of the underlying hydrologic model. The infiltration model adopted in TRIGRS is based on the linearized solution introduced by Iverson (2000) and extended to Richards' Equation by Baum et al. (2002), which describes the unsaturated Darcian flow due to the infiltration on the ground, in one vertical dimension, for a sloping surface. In this way, the TRIGRS approach allows us to describe the groundwater pressure head as a function of both the time and the vertical direction, assuming that the zone above the water table is tension-saturated to the ground surface. Therefore, the obtained perched water table can be either over the previously defined depth of slope failure, as typically happens in clay soils, or near the ground surface, as typically happens in prewetted sandy soils (Iverson, 2000). On the contrary, the SLIP model bypasses the transient analysis, assuming the formation, in consequence of a rainfall event, of the final condition of a perched water table, over the specified depth of slope failure. Furthermore, from a stability analysis perspective, the TRIGRS model does not take into account groundwater flow parallel to the slope, thus, neglecting the destabilizing filtration force (Zhan et al., 2007), which instead is correctly taken into account in the SLIP model.

\section{Models application and input parameters on a regional scale}

\subsection{SLIP}

The SLIP model has been implemented by using Matlab ${ }^{\circledR}$ and relies on a GIS framework tested on the study area. Figure 7 outlines the conceptual methodology of the SLIP model in order to carry out the slope-stability analysis on a regional scale. The territory is divided into a $20 \mathrm{~m} \times 20 \mathrm{~m}$ grid, where each elementary cell is independently modelled considering its own soil features. The slope angle is derived from a Digital Elevation Model (DEM) with an accuracy of $20 \mathrm{~m}$, whereas geotechnical data are derived from the most detailed lithological, geological and soil coverage data currently available. In particular, for the geotechnical characteristics of shallow soils, two complementary levels of information have been used. The first level is represented by the regional map on soil covers; the second level is represented 


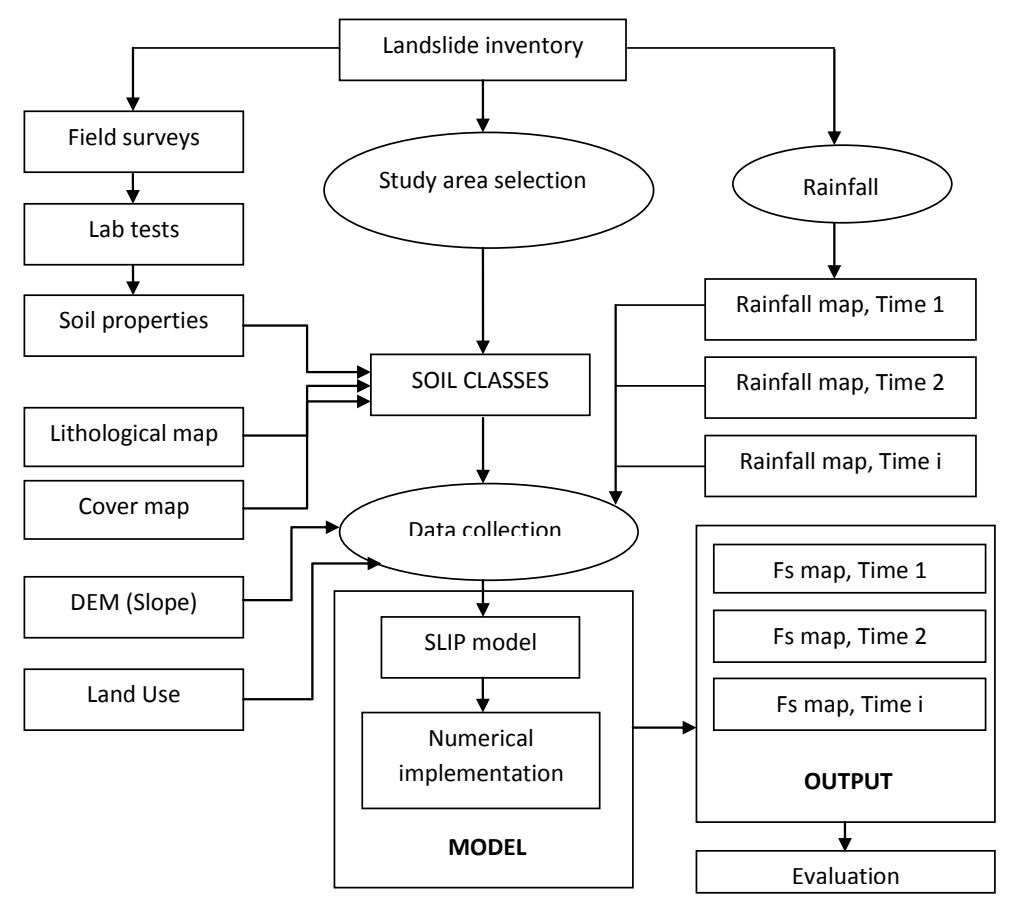

Fig. 7. Flow chart representing the conceptual methodology of the SLIP model for the slope-stability analysis on a regional scale.

by the lithological map, which has been used for those areas where some geological formations outcrop or there is a lack of information about soil covers. Both maps are on a scale of 1:10000. For what concerns the type of soils and the assessment of geotechnical parameters, a heuristic methodology, similar to that described by Cervi et al. (2010), has been adopted. On both the test area and the study area, six soil units have been derived from bedrock lithology and coverage data, by considering the resistance to weathering of the rock and the texture and grain size of the resulting soil. The values of geotechnical parameters of each soil unit, which are reported in Table 1, have been assigned on the basis of an extensive field measurement campaign in the study area and of a large number of laboratory tests on representative samples collected in the test-area. In particular, the soil unit No. 6 includes rocks and gypsum, and extends over $2.9 \%$ of the study area: it has been disregarded in the SLIP analysis because it is considered unconditionally stable.

Other model parameters, such as $A$ and $\lambda$, have been considered for each soil unit (Table 2), on the basis of the above-mentioned experimental results (Fredlund et al., 1996) and according to the soil classes reported in Montrasio and Valentino (2008).

As previously explained, the model parameter $\alpha$ has been considered equal to 3.4 everywhere, on the basis of experimental measurements. The coefficient $\xi$ (Eq. 11) is also considered as a constant calibration coefficient and has been assumed equal to 0.7 everywhere.
Table 1. Geotechnical parameters of the soil units in the study area.

\begin{tabular}{llrrrrr}
\hline $\begin{array}{l}\text { Soil } \\
\text { unit }\end{array}$ & $\begin{array}{l}\text { Type of } \\
\text { soil }\end{array}$ & $\%$ & $\begin{array}{r}\phi^{\prime} \\
\left(^{\circ}\right)\end{array}$ & $\begin{array}{r}c^{\prime} \\
(\mathrm{kPa})\end{array}$ & $\begin{array}{r}n \\
-\end{array}$ & $\begin{array}{c}G_{\mathrm{S}} \\
-\end{array}$ \\
\hline 1 & Clayey silt & 60 & 25 & $0-5$ & 0.46 & 2.7 \\
2 & Clay & 3.8 & $15-30$ & 10 & $0.35-0.55$ & 2.7 \\
3 & Sand & 7.8 & $30-35$ & 0 & $0.30-0.40$ & 2.7 \\
4 & Deposits & 13.1 & $30-35$ & $0-5$ & $0.40-0.50$ & 2.7 \\
5 & Shale & 12.4 & $15-30$ & $5-20$ & $0.35-0.55$ & 2.7 \\
6 & Rock, Gypsum & 2.9 & \multicolumn{6}{c}{ Excluded from the analysis } \\
\hline
\end{tabular}

It is worth to notice that some geotechnical parameters, such as $\phi^{\prime}, c^{\prime}$ and $n$, can assume values in given ranges (see Table 1). Different values of these parameters have been adopted in order to develop a sensitivity analysis on their effect on the results predicted by the SLIP model, only for the event of April 2005 on the test-area, as will be explained in the following.

After the calibration procedure on the test-area, only one set of parameters has been chosen to carry out the SLIP analysis on the wider study area over one year period. Table 2 shows, for each parameter, the values adopted for the simulations.

All input data are acquired, by the system, from a GIS data-base. For each parameter used in the model, a map is generated at the same spatial resolution $(20 \mathrm{~m} \times 20 \mathrm{~m})$. The input data are inserted into a "raster" form and refer to both 
Table 2. Input parameters for the SLIP analysis on one year period.

\begin{tabular}{ccccrcrrrrr}
\hline $\begin{array}{l}\text { Soil } \\
\text { unit }\end{array}$ & $\begin{array}{l}\text { Type of } \\
\text { soil }\end{array}$ & $\begin{array}{c}H \\
(\mathrm{~m})\end{array}$ & $\begin{array}{r}\phi^{\prime} \\
\left({ }^{\circ}\right)\end{array}$ & $\begin{array}{r}c^{\prime} \\
(\mathrm{kPa})\end{array}$ & $\begin{array}{r}\lambda \\
-\end{array}$ & $\begin{array}{r}A \\
-\end{array}$ & $\begin{array}{r}n \\
-\end{array}$ & $\begin{array}{r}G_{\mathrm{S}} \\
-\end{array}$ & $\begin{array}{r}K_{T} \\
\left(\mathrm{~d}^{-1}\right)\end{array}$ \\
\hline 1 & Clayey silt & 1.2 & 25 & 0 & 0.4 & 80 & 0.46 & 3.4 & 2.7 & 0.432 \\
2 & Clay & 1.2 & 20 & 10 & 0.4 & 100 & 0.50 & 3.4 & 2.7 & 0.086 \\
3 & Sand & 1.2 & 35 & 0 & 0.4 & 40 & 0.40 & 3.4 & 2.7 & 0.864 \\
4 & Deposits & 1.2 & 30 & 5 & 0.4 & 40 & 0.45 & 3.4 & 2.7 & 0.604 \\
5 & Shale & 1.2 & 20 & 20 & 0.4 & 100 & 0.35 & 3.4 & 2.7 & 0.259 \\
6 & Rock, Gypsum & \multicolumn{1}{c}{ Excluded from the analysis } \\
\hline
\end{tabular}

soil characteristics $\left(\phi^{\prime}, c^{\prime}, \alpha, \lambda, A, K_{T}, G_{\mathrm{s}}, n\right)$ and slope geometry $(\beta, H)$. In particular, for this application $H$ has been considered equal to $1.2 \mathrm{~m}$ everywhere, because this is the mean value of the unstable soil thickness determined by field measurements.

The degree of saturation $\left(S_{\mathrm{r}}\right)$ is influenced by climatic conditions and seasonal weather. Experimental measurements show that, at soil depths of interest in the study area, $S_{\mathrm{r}}$ generally ranges from a minimum of 0.6 (in summer) to a maximum of 0.9 (in winter) (Meisina and Scarabelli, 2007; Montrasio et al., 2010). For this reason, the value of $S_{\mathrm{r}}$ has been considered constant during each season and across the entire analysed area. In Table 3, the values of $S_{\mathrm{r}}$ considered in the model are shown, for each season, as function of the weather conditions.

It is worth noting that assuming $S_{\mathrm{r}}$ constant during each season is consistent with the claims that, in the SLIP model, (i) the slope stability (i.e., the Factor of safety) varies with the rainfall in a real-time manner and (ii) $S_{\mathrm{r}}$ is considered only as an initial state parameter for the daily stability analysis. The increase of $S_{\mathrm{r}}$, as a consequence of a daily rainfall, is implicitly taken into account by the increase of the parameter $m$, which is strictly related to the rainfall depth $(h)$ (Eq. 10). In order to simplify the model, it is assumed that all the infiltrated water accumulates at the bottom of the shallow soil layer $(H)$ and forms a saturated layer with thickness denoted as $H_{\text {sat }}$ (Fig. 5). Indeed, the same rainfall amount causes a variation of $S_{\mathrm{r}}$ in the whole $H$ layer, but not uniformly. On the other hand, the decrease of $S_{\mathrm{r}}$ is modelled through the negative exponential function of $m$ (Eq. 9).

The model relies on precipitation maps obtained from data measured by rain-gauges (Fig. 8). A rainfall input data, in terms of rainfall depth, is associated with each cell. The interpolation method used for the definition of the rainfall pattern is based on the inverse-square distance weighing method, applied to each point with respect to the position of the rain gauges, disregarding the altitude. Given the extension and the position of the study area, in the present work rainfall data coming from 13 rain-gauges have been considered. The location and altitude of the rain-gauges is shown on the map in Fig. 8, which shows an example of rainfall

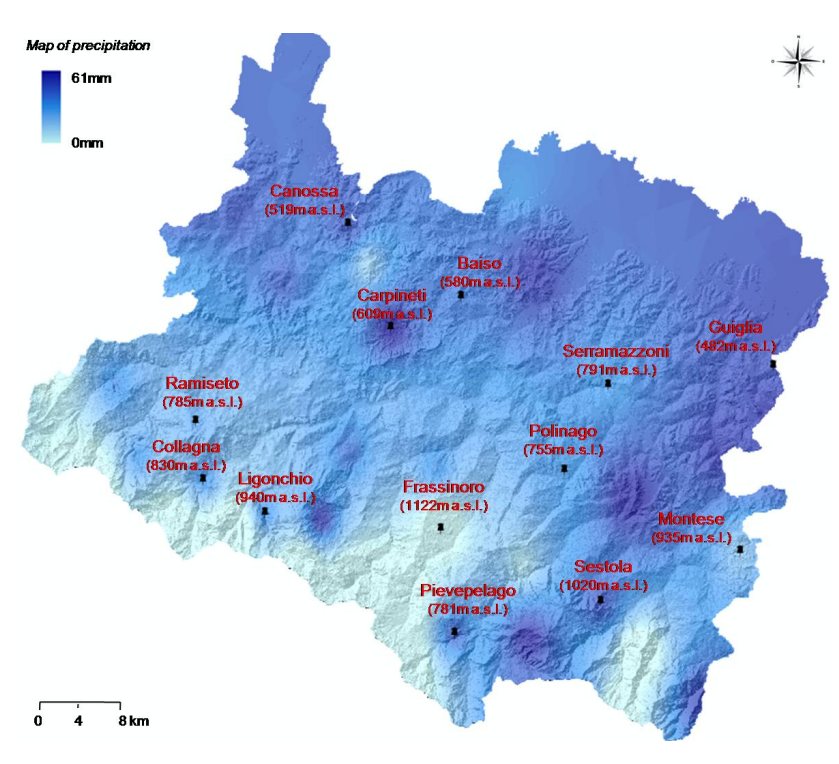

Fig. 8. Rain-gauge locations and example of rainfall distribution obtained after the application of the interpolation method on the study area for the rainfall event of the 11 April 2005.

distribution obtained after the application of the interpolation method.

As of today, the SLIP model runs operatively, twice a day, at the Centre of Civil Protection of Emilia Romagna Region in Bologna. The output of the model is given in terms of safety factor maps, which give the safety factor for each elementary cell $(20 \mathrm{~m} \times 20 \mathrm{~m})$ at a certain time.

Every $12 \mathrm{~h}$, the SLIP model produces a detailed safety factor map on the basis of the rainfall conditions over the last 30 days. The accumulation time step can be modified: in particular, it can be reduced, in the case of warning situations, to increase the refresh rate. In the following, for the sake of conciseness, only the results of relative to daily runs of the SLIP model are presented.

\subsection{TRIGRS}

The TRIGRS analysis has been carried out only for the event of April 2005 and only on the test-area $\left(370 \mathrm{~km}^{2}\right)$. Among 
Table 3. Values of the degree of saturation used in the SLIP model.

\begin{tabular}{llc}
\hline Season & Period & Degree of saturation $\left(S_{\mathrm{r}}\right)$ \\
\hline Summer & July-August & 0.60 \\
Autumn & September-October-November & 0.75 \\
Winter-Early Spring & December-January-February-March-April & 0.90 \\
Late Spring & May-June & 0.75 \\
\hline
\end{tabular}

the input parameters needed, the slope angle $(\beta)$ corresponding to each cell is derived from the DEM resolution of $20 \mathrm{~m}$. Geotechnical data have been assigned to each cell on the basis of the defined six soil units, which are summarized in Table 2. They have been chosen like previously described for the SLIP model. For what concerns the hydraulic diffusivity parameter, it has been evaluated according to the method reported in Bras (1990), considering the mean values of soil porosity and permeability of a silty loam, and assuming a value of diffusivity equal to $10^{-5} \mathrm{~m}^{2} \mathrm{~s}^{-1}$ everywhere.

A constant value for the soil thickness equal to $1.2 \mathrm{~m}$ has been assumed everywhere. As initial condition, a water table depth equal to $1.2 \mathrm{~m}$ from ground level, corresponding to the shallow soil thickness, was assumed. The mean hourly rainfall intensities recorded for $72 \mathrm{~h}$, during the April 2005 event, at the five rain gauges located in the test-area (Fig. 8), were assumed as boundary conditions at the slope surface.

\section{ROC analysis for the evaluation of models' reliability}

In order to quantify the spatial discrepancy between the actual landslides and prediction of a model, a further analysis of the obtained predictions for the event of April 2005, both for SLIP and TRIGRS model, has been carried out. The model reliability has been evaluated through a Receiver Operating Characteristic (ROC) analysis (Bagueria, 2006). Since the occurred landslides have been mapped as points (Fig. 2), to compare the overlapping between landslide areas and model results, each landslide area has been widened to include the surrounding four elementary cells, i.e., over a region with area equal to $40 \mathrm{~m} \times 40 \mathrm{~m}$.

There are the following four possible outcomes when classifying a grid from the unstable map: (i) if a computed unstable cell is inside the observed landslide area, it is counted as true positive (tp); (ii) if it is outside the observed landslide area, it is counted as false positive (fp); (iii) if a computed stable cell corresponds to an observed landslide cell, it is counted as false negative (fn); (iv) if a computed stable cell does not correspond to any observed landslide cell, it is called true negative (tn).

To reach the goal of the ROC analysis, two main quantities have been calculated: the sensitivity, defined as the ratio between tp and the sum of tp and fn, and the specificity, defined as the ratio between th and the sum of tn and fp. Different points of the ROC curve have been obtained by assuming, at each step, a different threshold value for the safety factor.

In the ROC graph, the sensitivity of the model is shown as a function of the specificity. The corresponding ROC curve indicates the ability of the model to correctly discriminate between positive and negative observations in the validation space. High sensitivity indicates a large number of correct predictions, whereas high specificity indicates a small number of false positives. By considering only stable/unstable condition, the only representative point in the ROC plot is that corresponding to $F_{\mathrm{S}}=1$. In the ROC analyses, explained in detail in the following, it has been decided to check the sensitivity and the specificity of the obtained results in correspondence to values of $F_{\mathrm{s}}$ higher than 1 , in order to account for areas that approach the instability condition during a storm event. Each point of the ROC curve has been obtained by considering different values of $F_{\mathrm{s}}$, until reaching the $100 \%$ of sensitivity. In this way, the area under the ROC curve can be interpreted as global statistical accuracy for the model. This statistical accuracy ranges from 0.5 (random prediction, represented by the diagonal straight line) to 1 (perfect prediction) and can be used both for comparison between the two models (Cervi et al., 2010) and for evaluation of the parametric analysis, coupled with appropriate considerations about the corresponding range of $F_{\mathrm{s}}$.

\section{Results of the slope-stability analyses}

\subsection{Test-area: comparison between SLIP and TRIGRS, event of 11 April 2005}

In order to carry out a preliminary parameter calibration, SLIP analysis has first been applied to the test-area for the event of the 10-11 April 2005. Figure 9 shows the $F_{\mathrm{s}}$ map resulting from the SLIP analysis on this area and the localization of the sites where soil slips actually occurred: black labels correspond, in fact, to the surveyed scars of soil slips. The correspondence between the red areas, where the SLIP model predicts an instability condition $\left(F_{\mathrm{S}} \leq 1\right)$, and the localization of the real events can be considered satisfactory from a qualitative point of view, even though it is clear that unstable areas are overestimated by the SLIP model. It can be supposed that the discrepancy between prediction and actual 


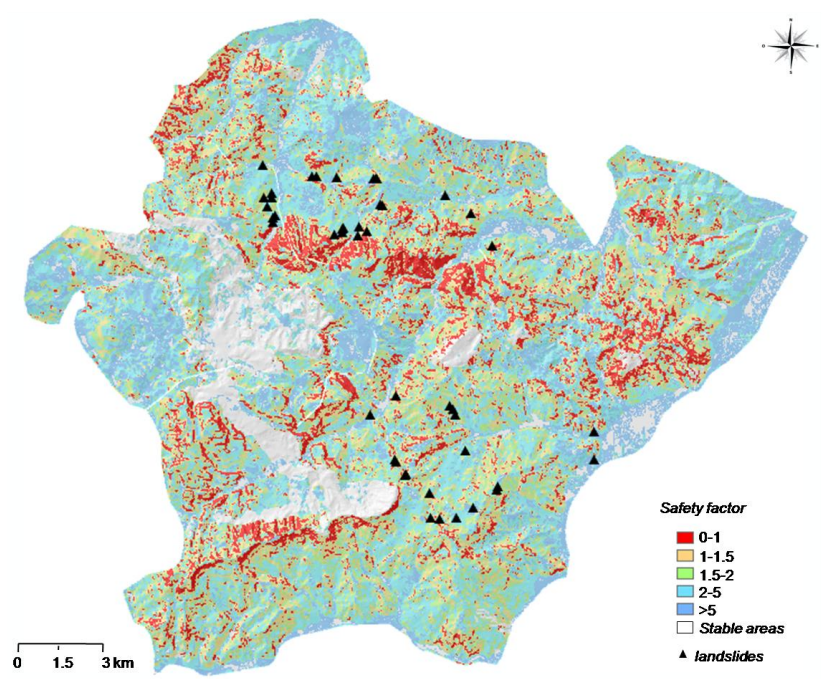

Fig. 9. SLIP analysis on the test-area: safety factor map and localization of soil slips occurred on the 11 April 2005.

event can be mainly due to the inaccuracy of input geotechnical parameters and, secondly, to the uncertainties in slope geometry and soil thickness.

Figure 10 shows the output of the TRIGRS model on the same area and for the same event. It is quite evident that, starting from the same set of input parameters, TRIGRS predicts a smaller number of unstable areas than SLIP. In Fig. 11, the ROC curves of the two models are directly compared. By considering, as most representative, the point corresponding to $F_{\mathrm{S}}=1$, SLIP has a specificity equal to 0.9 and a sensitivity equal to 0.22 (i.e., $22 \%$ of perfect prediction of true positives), whereas the sensitivity of TRIGRS is lower (i.e., only $2 \%$ of perfect prediction of true positives) and its specificity higher. The higher the reference value of $F_{\mathrm{s}}$, the higher the sensitivity and the lower the specificity for both models, even if SLIP behaves better than TRIGRS. Moreover, SLIP reaches the best prediction rate in correspondence to $F_{\mathrm{S}}=2.8$, while TRIGRS reaches the highest sensitivity in correspondence of $F_{\mathrm{s}}=5$. Obviously, the lower is the $F_{\mathrm{S}}$ value in correspondence to which the sensitivity is higher, the better the model behaves. The global accuracy (i.e., the area under the ROC curve) takes on the following values for the different stability analyses: 0.754 for SLIP and 0.686 for TRIGRS. The two deterministic models have very similar results in terms of prediction capability. In particular, the score obtained by the SLIP model reveals a fair prediction of shallow landslides and is slightly higher than that obtained by TRIGRS.

\subsection{Test-area: sensitivity analysis on SLIP parameters, event of 11 April 2005}

To clarify how geotechnical input parameters, namely the shear strength angle $\left(\phi^{\prime}\right)$, the effective cohesion $\left(c^{\prime}\right)$ and the

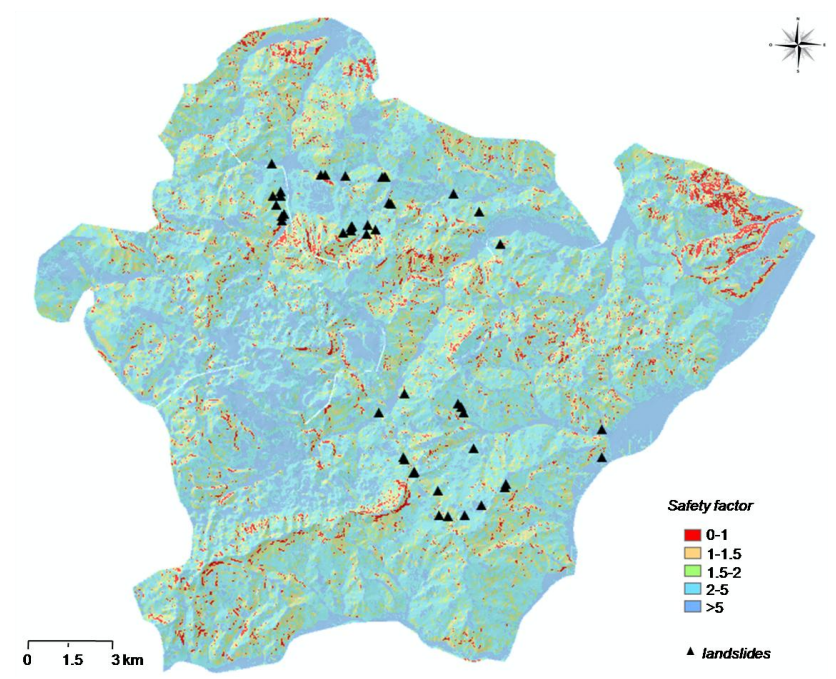

Fig. 10. TRIGRS analysis on the test-area: safety factor map and localization of soil slips occurred on the 11 April 2005.

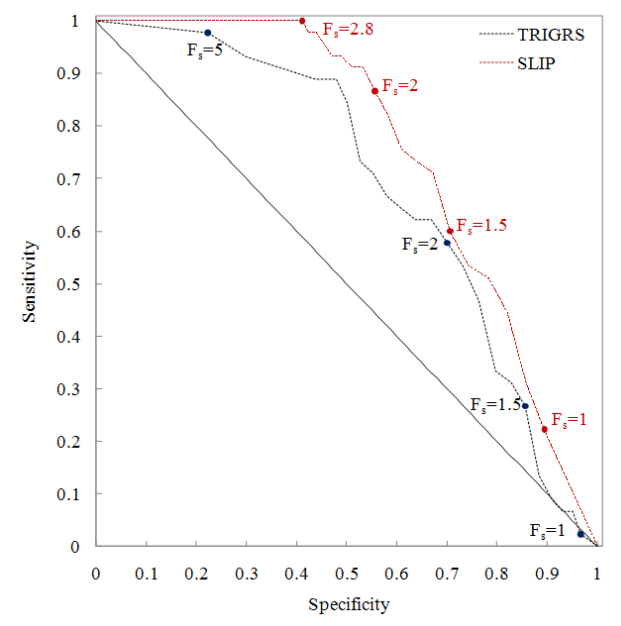

Fig. 11. ROC curves corresponding to SLIP and TRIGRS analyses on the test-area for soil slips occurred on the 11 April 2005.

porosity ( $n$ ) have been chosen for the SLIP analysis, it is worth to discuss the calibration procedure. A sensitivity analysis on the effect of different geotechnical parameters on the computed results has been carried out only for the event occurred on the 11 April 2005. A series of 16 analyses has been carried out on the test-area, and, for each of them, only one parameter has been changed with respect to the dataset shown in Table 2. For each geotechnical parameter, one or two further values, with respect to the corresponding values adopted for each soil unit (Table 2), have been considered (Table 4). Each SLIP analysis is identified with an identification number, which includes the soil unit involved, the considered parameter and the value assigned to the chosen parameter (Table 4). For each analysis, the ROC curve has been derived (Fig. 12) and the global accuracy (i.e., the area under 
Table 4. Values of input parameters $A$ and $\lambda$ for the SLIP sensitivity analyses.

\begin{tabular}{lccrcc}
\hline Analysis & $\begin{array}{r}\text { Soil unit } \\
\text { involved }\end{array}$ & $\begin{array}{c}\phi^{\prime} \\
\left({ }^{\circ}\right)\end{array}$ & $\begin{array}{r}c^{\prime} \\
(\mathrm{kPa})\end{array}$ & $\begin{array}{c}n \\
-\end{array}$ & $\begin{array}{c}\text { Global Accuracy } \\
-\end{array}$ \\
\hline SLIP $1 c 5$ & 1 & 25 & 5 & 0.46 & 0.717 \\
SLIP $2 \phi 15$ & 2 & 15 & 10 & 0.50 & 0.753 \\
SLIP $2 \phi 30$ & 2 & 30 & 10 & 0.50 & 0.757 \\
SLIP 2 c 0 & 2 & 20 & 0 & 0.50 & 0.745 \\
SLIP $2 n 0.35$ & 2 & 20 & 10 & 0.35 & 0.752 \\
SLIP $2 n 0.55$ & 2 & 20 & 10 & 0.55 & 0.755 \\
SLIP $3 \phi 30$ & 3 & 30 & 0 & 0.40 & 0.752 \\
SLIP $3 n 0.30$ & 3 & 35 & 0 & 0.30 & 0.751 \\
SLIP $4 \phi 35$ & 4 & 35 & 5 & 0.45 & 0.758 \\
SLIP $4 c 0$ & 4 & 30 & 0 & 0.45 & 0.742 \\
SLIP $4 n 0.40$ & 4 & 30 & 5 & 0.40 & 0.753 \\
SLIP $4 n 0.50$ & 4 & 30 & 5 & 0.50 & 0.756 \\
SLIP $5 \phi 15$ & 5 & 15 & 20 & 0.35 & 0.755 \\
SLIP $5 \phi 30$ & 5 & 30 & 20 & 0.35 & 0.759 \\
SLIP 5 5 & 5 & 20 & 5 & 0.35 & 0.743 \\
SLIP $5 n 0.55$ & 5 & 20 & 20 & 0.55 & 0.761 \\
\hline
\end{tabular}

the ROC curve) has also been calculated (Table 4). In particular, Fig. 12a shows the ROC plots referring to the results of SLIP analyses obtained for different values of $\phi^{\prime}$ for some soil units; Fig. 12b shows the ROC curves obtained after assigning different values of $c^{\prime}$, and Fig. 12c shows the ROC curves corresponding to different values of porosity $(n)$. The range of the considered $F_{\mathrm{S}}$ is between 1 and 2.8 for all the analyses, except for the SLIP-1-c-5, where the $100 \%$ of sensitivity is reached for $F_{\mathrm{s}}=5$. It can be noticed how the model results are scarcely influenced by the assumptions made for these geotechnical parameters, since the global accuracy remains substantially unchanged. This calibration procedure led to assume that the input parameters assigned to each soil unit, summarized in Table 2, were appropriate.

\subsection{SLIP analysis on the study area for events of 11 April and 3 December 2005}

After carrying out the calibration procedure on the test-area and only for the event of the 11 April 2005, the SLIP analysis has been extended to a wider study area (Fig. 2). Figure 13 shows three $F_{\mathrm{S}}$ maps resulting from the slope-stability analysis in this area. The three maps correspond, respectively, to the dates of the 9, 10 and 11 April 2005, in order to underline the evolution of the stability condition before and during the heavy rainfall (as an example, the rainfall distribution corresponding to the 10 April 2005 is reported in Fig. 8). Areas characterised by a safety factor close to one progressively become wider when the rainfalls become more intense. Figure $13 \mathrm{c}$, in particular, shows the comparison between the results of the slope-stability analysis and the localization of the sites where soil slips actually occurred, which are identified through black labels. The correspondence between the red areas, where the SLIP model predicts an instability condition $\left(F_{\mathrm{s}} \leq 1\right)$, and the localization of the real events can be considered satisfactory only from a qualitative point of view, since even in this case unstable areas appear overestimated by the SLIP model. Unfortunately, we had no information about the occurrence of any soil slip in the south-western part of the study area, which appears unstable from the model results. Nevertheless, the prediction capability of the SLIP model, which has been evaluated through the ROC plot, can be considered fairly good, with a global accuracy of 0.795 (Fig. 17a), with $F_{\mathrm{S}}$ ranging from 1 to 2.8 . In particular, by considering the most representative point corresponding to $F_{\mathrm{S}}=1$, SLIP has a specificity equal to 0.91 and a sensitivity equal to 0.22 .

Figure 14 shows the results of a similar analysis in correspondence to the event occurred on the 3 December 2005. In particular, Fig. $14 \mathrm{a}, \mathrm{b}$ and $\mathrm{c}$ shows the $F_{\mathrm{s}}$ maps referring, respectively, to two days before, to one day before, and to the same day when soil slips occurred. Figure 14c shows the correspondence between the predicted unstable areas (in red) and the localization of the real events (black dots). It is quite clear that, even in this case, unstable areas are overestimated by the SLIP model and the spatial correspondence is not completely satisfactory. However, the prediction capability of the SLIP model, which has been evaluated through the ROC curve, can be represented by the global accuracy equal to 0.750 (Fig. 17b), with $F_{\mathrm{s}}$ ranging from 1 to 5.7. By considering the most representative point corresponding to $F_{\mathrm{S}}=1$, SLIP presents better results in respect to the previous case, with a specificity of 0.97 and a sensitivity of 0.22 .

\subsection{Study area: SLIP analysis on one year period}

By using recorded daily rainfall data from the 1 January 2005 to the 30 June 2005, the SLIP analysis has been carried out on the entire study area for this six month period. The main goal of this preliminary analysis was to calibrate the input parameter set, on the basis of the field inventory of soil slips occurred on the 11 April 2005. The results of the timevarying analysis are summarized in Fig. 15a, which shows the daily percentage of cells characterised by $F_{\mathrm{S}} \leq 1$ (i.e., unstable conditions) with respect to the daily rainfall depth, over the six month time interval. The daily rainfall data shown in Fig. 15 represent the mean values from the 13 rain gauges considered for rainfall map construction (Fig. 8). It is worth noting that the unstable areas, in correspondence to the benchmark event of the 11 April 2005, are almost $14 \%$ of the entire study area. Thanks to the calibration procedure, the SLIP model allows to obtain a negligible or nil percentage of unstable areas all over the considered period, except for the expected date, in correspondence to which the prediction capability can be considered fairly good, as previously said.

The values of the input parameters used for the first calibration analysis have been kept constant to carry out the 

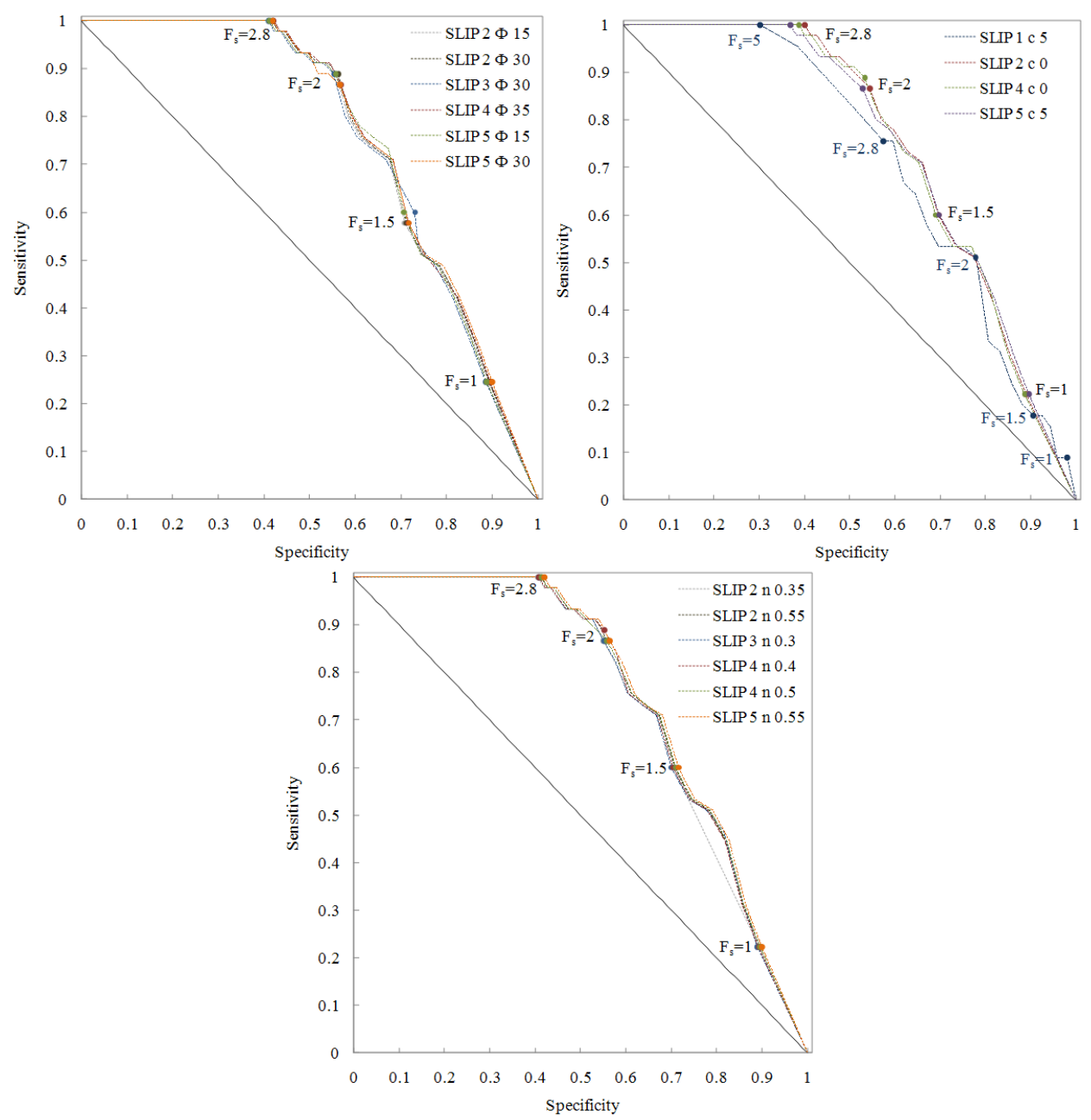

Fig. 12. ROC curves representing sensitivity analysis on soil parameters for the SLIP model (test-area, event of 11 April 2005): (a) results obtained for different values of $\phi^{\prime} ;(\mathbf{b})$ results obtained for different values of $c^{\prime} ;(\mathbf{c})$ results obtained for different values of porosity $(n)$.

SLIP analysis for the following six month period. The second time-varying SLIP analysis has been carried out from the 1 July to the 31 December 2005, and the obtained results are summarized in Fig. 15b. In correspondence to this period, a dozen of shallow landslides were reported to occur on the 3 December 2005 in the south-eastern part of the study area. From the diagram in Fig. 15b, it can be noticed how the unstable areas on the 3 December 2005 are about $3 \%$. As previously explained, the ROC analysis for this event shows how the prediction capability can be considered rather fair. On the other hand, time-varying percentage of unstable areas (Fig. 15b) shows how other rainfall events of higher or equal intensity, such as those occurred in September and November 2005, respectively, are not associated with extended instability conditions.

\subsection{The influence of land use}

In order to improve the prediction capability of the SLIP model, a further analysis has been carried out, taking into account that due to land use some areas can be considered undoubtedly stable. The SLIP analysis was applied on the entire study area, in correspondence of the two events of the 11 April and 3 December 2005 (Fig. 16). By considering the map reporting the use of different areas (CORINE MAP Scale 1:100000), the following areas have been disregarded for the slope-stability analysis: unbroken urban areas, industrial and commercial areas, urban gardens and parks, ricefields, beaches, rock outcrops and bodies of water. In particular, unbroken urban areas have been disregarded because field surveys on actual landslides revealed that soil slips did not occur on these kind of areas. Moreover, unbroken urban areas can be considered rather impervious to rainfall water. In this way some areas, which appear white colored in $F_{\mathrm{S}}$ maps in Fig. 16, are considered unconditionally stable. The 




Fig. 13. SLIP analysis on the study area: time-varying maps of $F_{\mathrm{S}}$ corresponding to the events occurred in April 2005 (14\% of unstable areas). (a) $F_{\mathrm{S}}$ map on the 9 April 2005; (b) $F_{\mathrm{S}}$ map on the 10 April 2005; (c) $F_{\mathrm{S}}$ map on the 11 April 2005. Each elementary cell is $20 \mathrm{~m} \times 20 \mathrm{~m}$.

prediction capability of the SLIP model coupled with information from CORINE map has been evaluated through the ROC plot and is better than that obtained through the model while disregarding land use (Fig. 17). In fact, the global accuracy of the SLIP analysis is 0.811 and 0.771 , for the two events of the 11 April and 3 December 2005, respectively (Fig. 17), with a slightly higher specificity in correspondence of $F_{\mathrm{S}}=1$ in both cases.

\section{Discussion on the results}

Even though the forecasting ability of physically based models on regional scale presents some criticisms, some advan- tages can be stressed. Results obtained through both SLIP and TRIGRS analyses present two types of problems: the first one is mainly linked with the intrinsic complexity of the triggering mechanism of shallow landslides, and the second regards the several limitations of simplifying the phenomenon through a physically based model.

The shallow landslides present different characteristics depending on geographic position, climate changes and geological boundary conditions. It is worth noting, for example, that the daily rainfall that caused many shallow landslides in the study area is far less than those causing the same kind of landslides in the tropics (Jotisankasa et al., 2008,2010 ); but it seems that the triggering mechanism of soil slips, in the study area, is more sensitive to the previous 


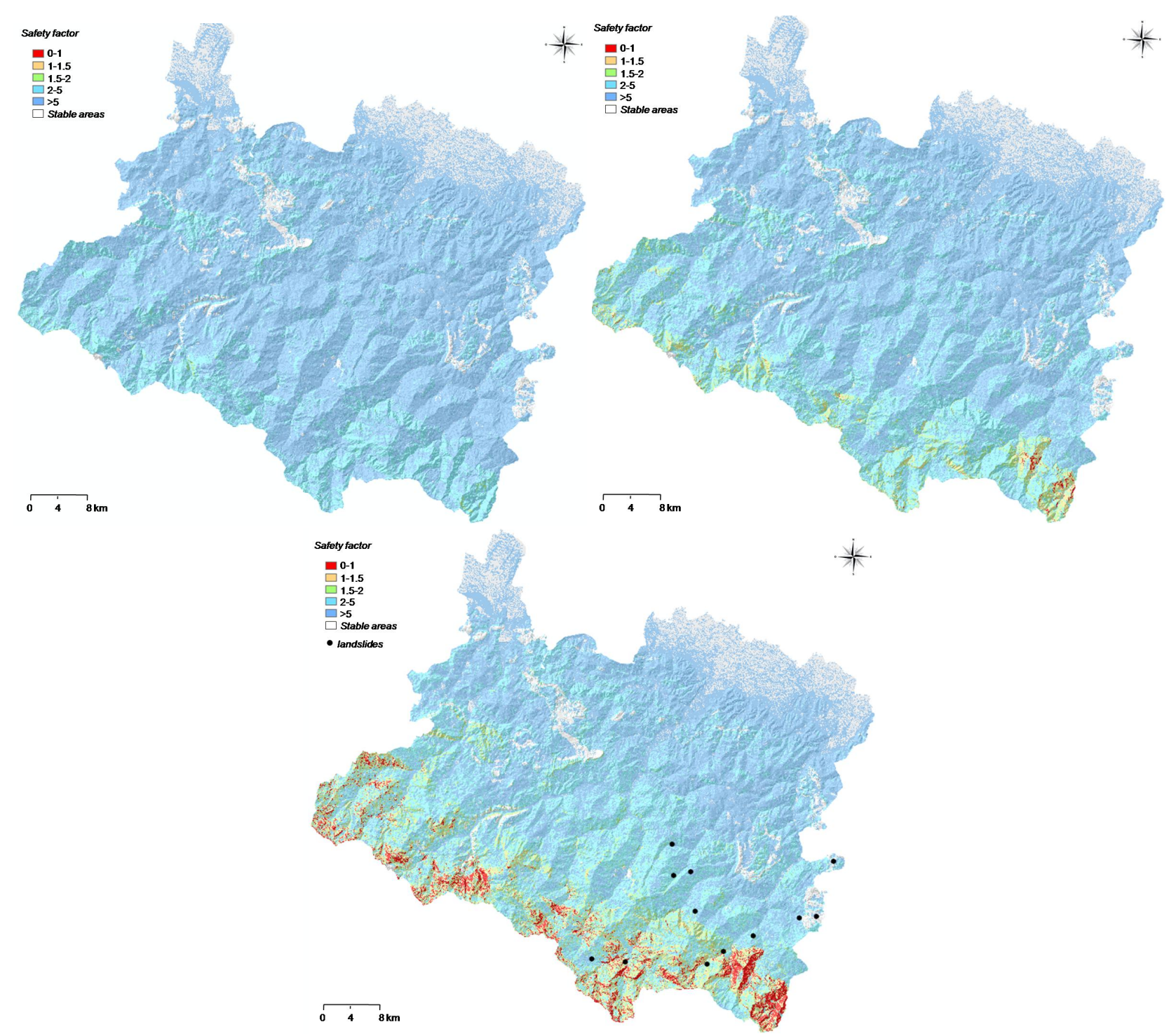

Fig. 14. SLIP analysis on the study area: time-varying maps of $F_{\mathrm{S}}$ corresponding to the events occurred in December 2005 ( $3 \%$ of unstable areas). (a) $F_{\mathrm{S}}$ map on the 1 December 2005 ; (b) $F_{\mathrm{S}}$ map on the 2 December 2005; (c) $F_{\mathrm{S}}$ map on the 3 December 2005 . Each elementary cell is $20 \mathrm{~m} \times 20 \mathrm{~m}$.

cumulated rainfall than to daily or hourly rainfall. As stated by Larsen and Simon (1993), geomorphological and climatological differences between humid-tropical and temperate environments may not be significant when hillslopes receive large amounts of rainfall over a prolonged period. Moreover, the climatic characteristics of the Italian Apennine favour the persistence of nearly saturated conditions of shallow soils for a long time during winter (Valentino et al., 2011). Then, the rainfall of the 10 April and of the 3 December 2005 fell on a shallow soil that was already near full saturation, mainly because of the previous rainfall, and, partly, because of the spring snowmelt. These considerations suggest the use of models which take into account existing soil moisture conditions and previous rainfalls.
Notwithstanding the presence of complex stratigraphy, a relevant limitation consists of the fact that uniform geological structures have been assumed as initial conditions in the simulations of the models for the analysed slopes. It is well known that neglecting various geological features limits the prediction skills of physically-based models.

The obtained results also suffer from the limited spatial variances of the soil parameters. In fact, the physical and mechanical properties of the same type of soil in different places may vary in a certain range, so that the assignment of the same values to geotechnical parameters on wide areas can reduce the modelling accuracy. On the other hand, in the present work, it has been shown how the SLIP model is scarcely influenced by a variation in soil strength parameters. 

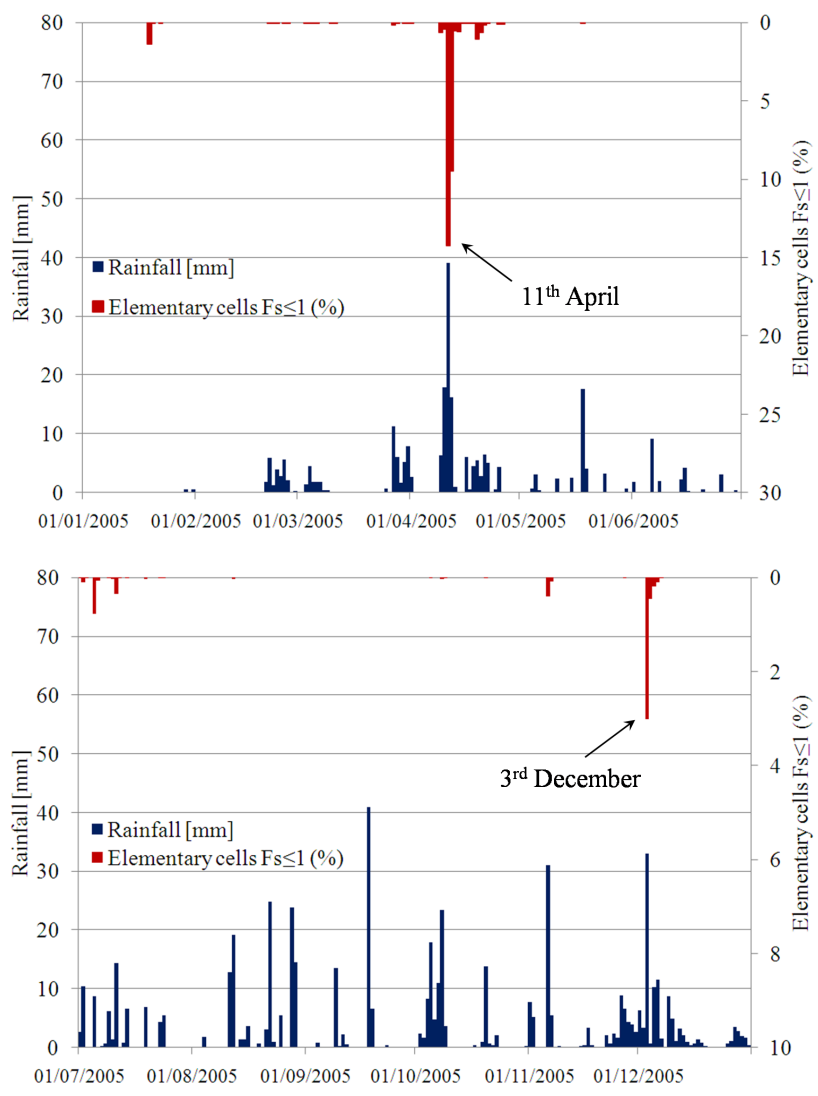

Fig. 15. SLIP analysis on the study area: daily percentage of cells characterised by $F_{\mathrm{S}} \leq 1$ (unstable condition) with respect to the daily mean rainfall depth. (a) calibration period, from the 1 January to the 30 June 2005; (b) prediction period, from the 1 July to the 31 December 2005.

Therefore, it can be stated that, by the same standards of other physically-based models (such as TRIGRS), SLIP can give useful results for the assessment of shallow landslide susceptibly in cases where there is a paucity of measured input data if reasonable assumptions are made regarding input values (Salciarini et al., 2006).

In the present work, the overprediction of unstable areas could be mainly due to the unfit spatial resolution of DEM, together with the assumption of a constant thickness of shallow potentially unstable soil. A higher spatial resolution of DEM and a detailed assessment of potentially unstable soil thickness could be used to derive better topographical features of slopes.

Furthermore, the presented simulations allow to underline some main differences between SLIP and TRIGRS.

1. While TRIGRS allows to take into account the transient effects of rainfall infiltration on pressure head in the tension-saturated zone between the perched water table and the ground surface, SLIP requires the degree of saturation $\left(S_{\mathrm{r}}\right)$ as initial state condition of the soil and, thanks to Eq. (11), it allows to take into account the previous soil moisture condition, on the basis of the rainfalls over the previous 30 days.

2. TRIGRS requires the knowledge of initial groundwater conditions (Godt et al., 2008). If detailed information on groundwater conditions is unavailable, proper parametric studies, assuming a range of initial conditions, are needed. SLIP does not take into account this kind of boundary condition, but the thickness of the perched water table $\left(H_{\text {sat }}=\mathrm{mH}\right)$ is calculated by the model, at each time step, as a function of daily rainfalls.

3. TRIGRS allows a more accurate description of slope hydrology, but is difficult to apply at a regional scale on wide areas, because of the large number of parameters to be introduced. Model results are also very sensitive to the initial conditions, particularly the steady component of the flow field and initial depth of the water table (Salciarini et al., 2006).

4. Thanks to its simplified formulation, the SLIP model allows a "dynamic" (i.e., time-varying) stability analysis on a large scale with a very low time-consuming computation, while TRIGRS requires a much longer computational time for a rainfall event lasting some days. This fundamental difference considers the SLIP model as a potential real-time tool for territory management.

Even though an improvement is needed, the ROC analysis has shown that the prediction capability of the two deterministic models, which display very similar results for the same parameter set, is fairly good. In particular, the score obtained by the SLIP model is slightly higher than that obtained by TRIGRS. By considering the most representative point of the ROC plot corresponding to $F_{\mathrm{S}}=1$, SLIP has relatively high specificity, but a low sensitivity, while TRIGRS presents a lower sensitivity rate in respect to a higher value of specificity.

On the basis of the SLIP analysis carried out over a one year time period (Fig. 15), it can be concluded that the application of the SLIP model on a regional scale predicts the soil slips occurrence more effectively time-wise than spatially. It can be stated, in fact, that over a one year period, only the two events corresponding to the expected dates, i.e., when soil slips actually occurred, appear really significant. In correspondence to a few other dates, the model gives instability conditions over a negligible percentage of the study area. Moreover, it is possible to underline that the time-varying percentage of the unstable areas reveals further positive aspects of the modelling. In fact, it can be observed that, in correspondence to some intense rainfall events, for example, those occurred during the summer and the fall of 2005, the model does not predict any slope instability. This scenario can be considered substantially correct, since the Geological Service of Emilia Romagna Region, which gathers any kind 


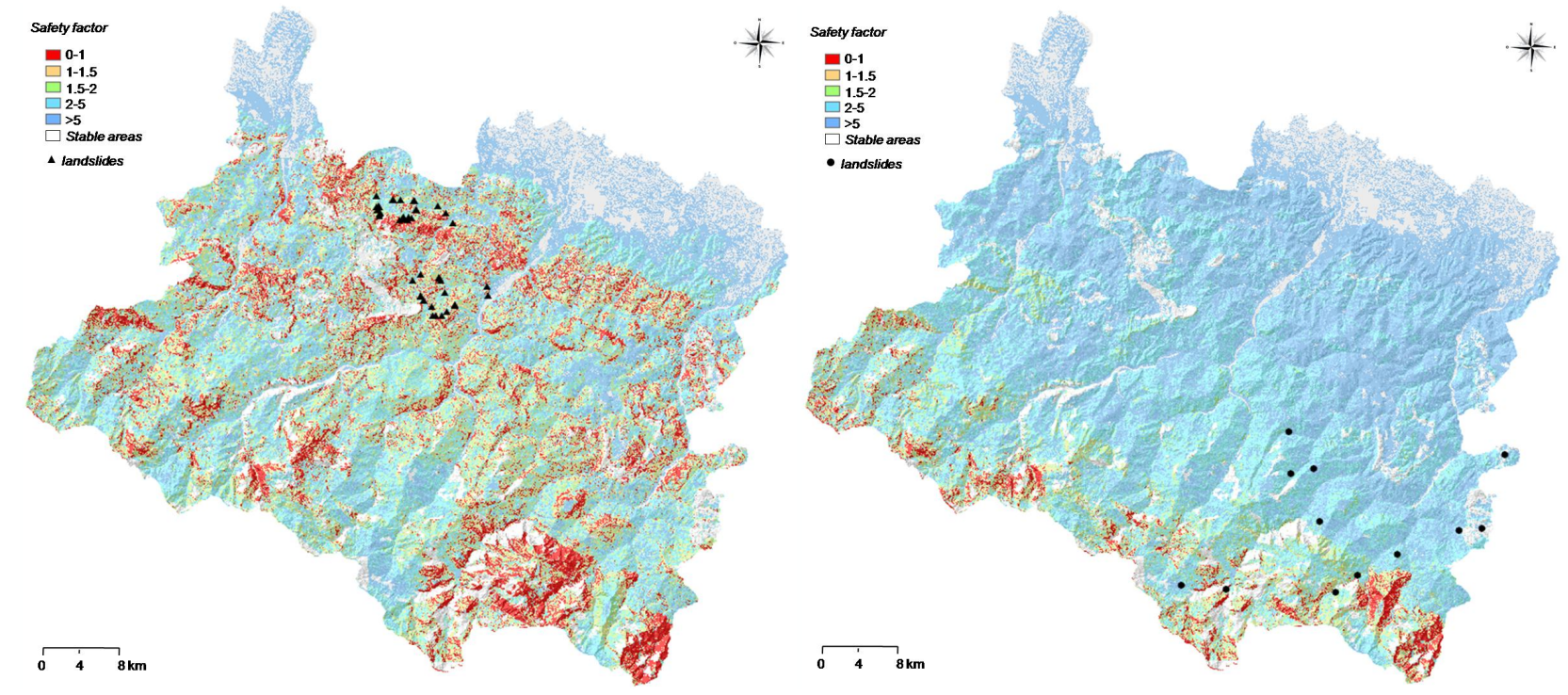

Fig. 16. Influence of land use on the SLIP analysis for the study area: (a) $F_{\mathrm{S}}$ map on the 11 April 2005; (b) $F_{\mathrm{S}}$ map on the 3 December 2005.
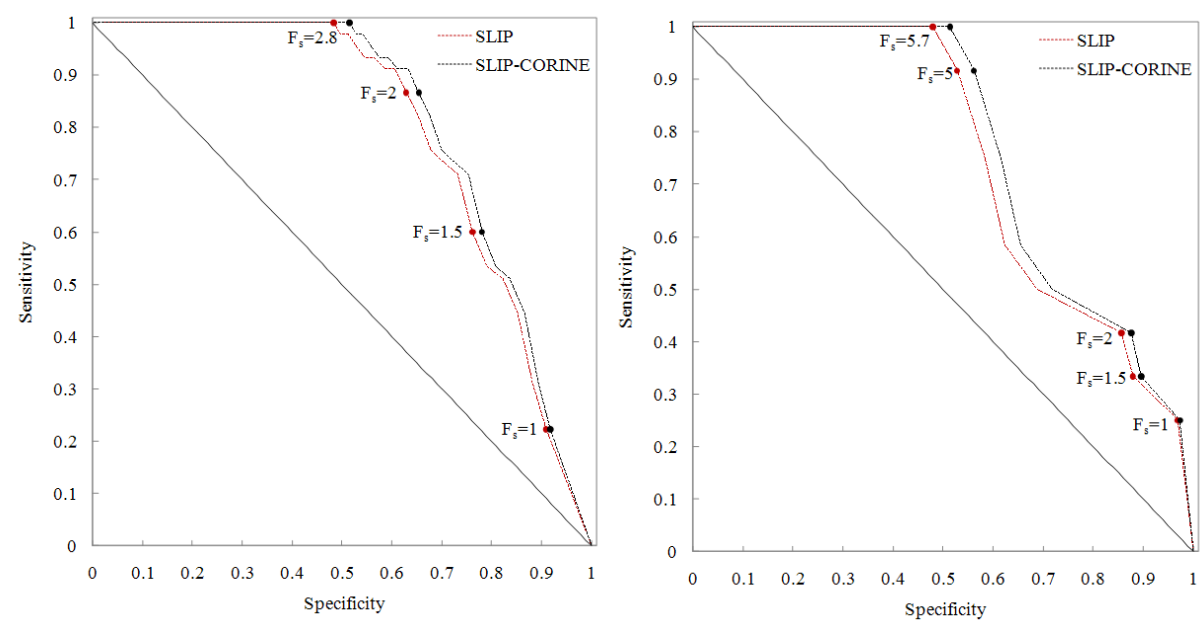

Fig. 17. ROC curves representing the prediction capability of the SLIP model applied on the study area, with and without the information on land use from CORINE map: (a) SLIP analyses on the 11 April 2005; (b) SLIP analyses on the 3 December 2005.

of information about slope instability phenomena occurred in the study area, confirmed that our reference landslides inventory of the year 2005 was sufficiently up-to-date and reliable in terms of timing, even if not complete in terms of landslide localization. In this case, it is possible to conclude that the model performs well, thanks to the capability of taking into account the existing soil moisture conditions together with the rainfall of previous days.

\section{Concluding remarks}

Some recent case-histories of soil slips occurred during 2005 in the Emilian Apennine (Northern Italy) have been considered. The study area has been briefly described from geological and meteorological viewpoints.

A slope-stability analysis on a regional scale has been carried out through the application of two physically-based stability models: SLIP (Shallow Landslides Instability Prediction) and TRIGRS (Transient Rainfall Infiltration and Gridbased Regional Slope-stability analysis). Advantages and limitations of these models have been discussed with respect to future applications of landslide assessment and prediction over large scales.

Due to the limited definition of the input dataset, we first performed both a calibration and a sensitivity analysis on a relatively small test-area, in order to define the appropriate spatial distribution of material properties. In the second 
phase, the SLIP analysis was extended to the wider study area. The simulation output is given in terms of safety factor maps, with a grid resolution of $20 \mathrm{~m}$. In the paper, only maps corresponding to the 10-11 April 2005 and to the 23 December 2005 (when soil slips actually occurred) have been shown. A ROC analysis of the obtained results on the test-area has shown that the prediction capability of the SLIP model is fairly good and displays very similar results with respect to TRIGRS.

Model simulations show that reasonable estimates of the slope angle, based on a DEM grid of $20 \mathrm{~m}$, and soil thickness, based on a limited number of measurements in the study area, can produce acceptable results. As other physically based models, such as TRIGRS, SLIP also requires the knowledge of the spatial distribution of physical properties and geotechnical parameters (Salciarini et al., 2006). From our simulations, this appears to be fundamental for an accurate calibration of the model. As we have explained, the spatial distribution of material properties can be reasonably inferred from geological maps and a limited number of lab tests.

Thanks to a very fast computation, SLIP analyses have been carried out over a one year observation interval, by keeping constant the input parameters used for the first calibration procedure. The time-varying percentage of unstable areas over the entire year 2005 was also analysed. The temporal accuracy of the SLIP model seems to be satisfactory, since a considerable percentage of unstable areas corresponds to the expected dates. Moreover, the time-varying percentage of unstable areas reveals that in correspondence to other intense rainfall events, the model does not predict slope instability. One of the main advantages of this approach consists of the fact that its results can be compared with historical, real-time and forecast rainfall information (Godt et al., 2008b).

The model's overestimation and the lack of spatial accuracy considers the results predicted by SLIP "acceptable" not in an "absolute" sense, but only with respect to timevarying results and, especially in its use as a predictive tool, with respect to the low spatial resolution of forecast rainfall information. In particular, the comparison between the actual observed soil slips' localization and the prediction of the SLIP model in the expected dates provides an assessment of the model reliability. An evident limitation is the fact that the model tends to overestimate the areas potentially subject to shallow landslides. In order to reach a better result in terms of spatial correspondence between prediction and actual slope failures, the authors think that a higher level of accuracy could be reached after a well-defined evaluation of input geotechnical parameters. Secondly, a smaller number of uncertainties in slope geometry can be obtained with a higher DEM resolution and with a detailed information about the thickness of potentially unstable shallow soil layers.

As already observed by some authors for TRIGRS (Salciarini et al., 2006; Godt et al., 2008a), even SLIP can be considered generally useful for preliminary assessments of slope stability over large areas, but it cannot provide assessments of stability for specific sites, with the exception of its application at a local scale, on the basis of more detailed data.

The results provided by SLIP in this study should be considered preliminary assessments of slope stability, because sparse and locally measured data were generalized to a large area. However, we can state that, similarly to TRIGRS, SLIP can give useful results for the assessment of shallow landslide susceptibility even in the cases where there is a paucity of measured input data, provided that reasonable assumptions on input values are made (Salciarini et al., 2006). The positive contribution of the SLIP model, with respect to TRIGRS, is its simplified formulation, which allows for the carrying out of a "dynamic" (i.e., time-varying) stability analysis on territory scale with a very low time-consuming computation, while TRIGRS requires a much longer computational time for a rainfall event lasting some days.

These results suggest that the output of the SLIP model could be used to define different levels of "dynamic" susceptibility. Moreover, if coupled with a model of forecast rainfall, SLIP could be the basis for the development of an early-warning alert system against the phenomena of interest.

Acknowledgements. The present study is financially supported by Geological Survey and ARPA-SIM Agency of Emilia Romagna Region, by CIMA Foundation (Savona - Italy) and by the Department of National Civil Protection. The authors would like to thank Alessandro Corsini (University of Modena and Reggio Emilia) for kindly providing the inventory dataset of site localizations used in this study. The authors would also like to thank Paola Reichenbach, Apiniti Jotisankasa and the other anonymous reviewer for their valuable comments.

Edited by: P. Reichenbach

Reviewed by: A. Jotisankasa and R. Baum

\section{References}

Aleotti, P.: A warning system for rainfall-induced shallow failures, Eng. Geol., 73, 247-265, 2004.

Apip, Takara, K., Yamashiki, Y., Sassa, K., Ibrahim, A. B., and Fukuoka, H.: A distributed hydrological-geotechnical model using satellite-derived rainfall estimates for shallow landslide prediction system at a catchment scale, Landslides, 7(3), 237-258, 2010.

Bagueria, S.: Validation and evaluation of predictive models in hazard assessment and risk management, Nat. Hazards, 37, 315329, 2006.

Bai, S. B., Wang, J., LÜ, G. N., Zhou, P. G., Hou, S. S., and Xu, S. N.: GIS-based and data-driven bivariate landslide-susceptibility mapping in the three gorges area, Pedosphere, 19(1), 14-20, 2009.

Baum, R. L. and Godt, J. E.: Early warning of rainfall-induced shallow landslides and debris flows in the USA, Landslides, 7(3), 259-272, 2010. 
Baum, R. L., Savage, W. Z., and Godt, J. W.: TRIGRS - a Fortran program for transient rainfall infiltration and grid-based regional slope stability analysis, US Geological Survey Open-File Report 2002-424, 38 pp., 2002.

Baum, R. L., Savage, W. Z. and Godt, J. W.: TRIGRS - A FORTRAN program for transient rainfall infiltration and grid-based regional slope stability analysis, version 2.0, US Geological Survey Open-File Report 2008-1159, 75 pp., 2008.

Borga, M., Dalla Fontana, G., Da Ros, D., and Marchi, L.: Shallow landslides hazard assessment using a physically based model and digital elevation data, Environ. Geol., 35(2-3), 81-88, 1998.

Borga, M., Dalla Fontana, G., and Cazorzi, F.: Analysis of topographic and climatic control on rainfall-triggered shallow landsliding using a quasi-dynamic wetness index, J. Hydrol., 268, 56-71, 2002.

Bras, R. L.: Hydrology: An Introduction to Hydrologic Science, Addison-Wesley Publishing Company, New York, USA, 1990.

Burton, A. and Bathurst, J. C.: Physically based modelling of shallow landslide sediment yeld at a catchment scale, Environ. Geol., 35(2-3), 89-99, 1998.

Campbell, R. H.: Debris flows originating from soil slips during rainstorms in Southern California, Q. J. Eng. Geol., 7, 339-349, 1974.

Campbell, R. H.: Soil slips, debris flow and rainstorms in the Santa Monica Mountains and Vicinity, Southern California, US Geological Survey Professional Paper 851, 1975.

Capparelli, G. and Tiranti, D.: Application of the MoniFLaIR early warning system for rainfall-induced landslides in Piedmont region (Italy), Landslides, 7(4), 401-410, 2010

Capparelli, G. and Versace, P.: FLaIR and SUSHI: two mathematical models for early warning of landslides induced by rainfall, Landslides, 8(1), 67-79, 2011.

Cardinali, M., Galli, M., Guzzetti, F., Ardizzone, F., Reichenbach, P., and Bartoccini, P.: Rainfall induced landslides in December 2004 in south-western Umbria, central Italy: types, extent, damage and risk assessment, Nat. Hazards Earth Syst. Sci., 6, 237260, doi:10.5194/nhess-6-237-2006, 2006.

Carrara, A., Cardinali, M., Detti, R., Guzzetti, F., Pasqui, V. and Reichenbach, P.: GIS techniques and statistical models in evaluating landslide hazard, Earth. Surf. Proc. Land., 16(5), 427-445, 1991.

Castronuovo, A.: Predisposizione al dissesto per frane superficiali del medio e basso Appennino della provincia di Reggio Emilia, Master Science Thesis, University of Modena and Reggio Emilia, 2005 (in Italian).

Cervi, F., Berti, M., Borgatti, L., Ronchetti, F., Manenti, F., and Corsini, A.: Comparing predictive capability of statistical and deterministic methods for landslides susceptibility mapping: a case study in the northern Apennines (Reggio Emilia Province, Italy), Landslides, 7(4), 433-444, 2010.

Crosta, G.: Regionalization of rainfall thresholds: an aid to landslide hazard evaluation, Environ. Geol., 35(2-3), 131-145, 1998.

Crosta, G. B. and Frattini, P.: Distributed modelling of shallow landslides triggered by intense rainfall, Nat. Hazards Earth Syst. Sci., 3, 81-93, doi:10.5194/nhess-3-81-2003, 2003.

Crosta, G. B., Dal Negro, P., and Frattini, P.: Soil slips and debris flows on terraced slopes, Nat. Hazards Earth Syst. Sci., 3, 31-42, doi:10.5194/nhess-3-31-2003, 2003.

Cruden, D. M. and Varnes, D. J.: Landslide types and processes, in:
Landslides: investigation and mitigation edited by: Turner, A. K. and Schuster, R. L., Sp. Rep. 247, Transportation Research Board, National Re-search Council, National Academy Press, Washington DC, 36-75, 1996.

Ellen, S. D. and Fleming, R. W.: Mobilization of debris flow from soil slips, San Francisco Bay Region, California, in: Debris flow/avalanches: process, recognition and mitigation, edited by: Costa, J. E. and Wieczorek, G. F., Geological Society of America, Reviews in Engineering Geology, 7, 31-40, 1987.

Fredlund, D .G., Xing, A., Fredlund, M. D., and Barbour, S. L.: The relationship of the unsaturated soil shear strength to the soil-water characteristic curve, Can. Geotech. J., 33(3), 440-448, 1996.

Godt, J. W., Baum, R. L., Savage, W. Z., Salciarini, D., Schulz, W. H., and Harp, E. L.: Transient deterministic shallow landslide modelling: requirements for susceptibility and hazard assessments in a GIS framework, Eng. Geol., 102, 214-226, 2008a.

Godt, J. W., Schulz, W. H., Baum, R. L., and Savage, W. Z.: Modeling rainfall conditions for shallow landsliding in Seattle, Washington, Reviews in Engineering Geology, 20, 137-152, doi:10.1130/2008.4020(08), 2008b.

Guzzetti, F., Peruccacci, S., Rossi, M., and Stark, C. P.: Rainfall thresholds for the initiation of landslides in central and southern Europe, Meteorol. Atmos. Phys., 98, 239-267, 2007.

Guzzetti, F., Peruccacci, S., Rossi M., and Stark, C. P.: The rainfall intensity-duration control of shallow landslides and debris flows: an update, Landslides, 5(1), 3-17, 2008.

Iiritano, G., Versace, P., and Sirangelo, B.: Real-time estimation of hazard for landslides triggered by rainfall, Environ. Geol., 35(23), 175-183, 1998.

Iovine, G., Di Gregorio, S., and Lupiano, V.: Debris-flow susceptibility assessment through cellular automata modelling: an example from 15-16 December 1999 disaster at Cervinara and San Martino Valle Caudina (Campania, southern Italy), Nat. Hazards Earth Syst. Sci., 3, 457-468, doi:10.5194/nhess-3-4572003, 2003.

Iverson, R. M.: Landslide triggering by rain infiltration, Water Resour. Res., 36(6), 1897-1910, 2000.

Jotisankasa, A. and Tapparnich, J.: Shear and soil-water retention behavior of a variably saturated residual soil and its implication on slope stability. In: Unsaturated Soils, edited by: Alonso, E. and Gens, A., Proc. of the 5th Int. Conf. on Unsaturated Soils UNSAT 2010, Barcelona, Spain, CRC Press, 1249-1254, 68 September 2010.

Jotisankasa, A., Kulsuwan, B., Toll, D. M. and Rahardjo, H.: Studies on rainfall-induced landslide in Thailand and Singapore. In: Unsaturated soils: Advances in Geo-Engineering, edited by: Toll, D. G., Augarde, C. E., Gallipoli, D., and Wheeler, S. J., Proc. First European Conference on Unsaturated Soils, Durham, UK, Taylor and Francis, London, 901-907, 2-4 July 2008.

Kesseli, J. E.: Disintegrating soil slips of the Coast Ranges of Central California, J. Geol., 51(5), 342-352, 1943.

Kim, D., Im, S., Lee, S. H., Hong, Y., and Cha, K. S.: Predicting the rainfall-triggered landslides in a forested mountain region using TRIGRS model, J. Mt. Sci., 7, 83-91, doi:10.1007/s11629-0101072-9, 2010.

Larsen, M. C. and Simon, A.: A rainfall intensity-duration threshold for landslides in a humid-tropical environment, Puerto Rico, Geogr. Ann. A, 75, 13-23, 1993. 
Liao, Z., Hong, Y., Wang, J., Fukuoka, H., Sassa, K., Karnawati, D., and Fathani, F.: Prototyping an experimental early warning system for rainfall-induced landslides in Indonesia using satellite remote sensing and geospatial datasets, Landslides, 7(3), 317324, 2010a.

Liao, Z., Hong, Y., Kirschbaum, D., Adler, R. F., Gourley, J. J., and Wooten, R.: Evaluation of TRIGRS (transient rainfall infiltration and grid-based regional slope-stability analysis)'s predictive skill for hurricane-triggered landslides: a case study in Macon County, North Carolina, Nat. Hazards, doi:10.1007/s11069-0109670-y, 2010b.

Lu, N. and Godt, J. W.: Infinite-slope stability under steady unsaturated seepage conditions, Water Resour. Res., 44, W11404, doi:10.1029/2008WR006976, 2008.

Meisina, C.: Swelling-shrinking properties of weathered clayey soils associated with shallow landslides, Q. J. Eng. Geol. Hydroge., 37, 77-94, 2004.

Meisina, C. and Scarabelli, S.: A comparative analysis of terrain stability models for predicting shallow landslides in colluvial soils, Geomorphology, 87, 207-223, 2007.

Montgomery, D. R. and Dietrich, W. E.: A physically based model for the topographic control of shallow landsliding, Water Resour. Res., 30, 1153-1171, 1994.

Montrasio, L.: Stability analysis of soil slip, in: Proc. of International Conf. "Risk 2000", edited by: Brebbia, C. A., Wit Press, Southampton, 357-366, 2000.

Montrasio, L. and Valentino, R.: Experimental analysis and modelling of shallow landslides, Landslides, 4, 291-296, 2007.

Montrasio, L. and Valentino, R.: A model for triggering mechanisms of shallow landslides, Nat. Hazards Earth Syst. Sci., 8, 1149-1159, doi:10.5194/nhess-8-1149-2008, 2008.

Montrasio, L., Valentino, R., and Losi, G. L.: Rainfall-induced shallow landslides: a model for the triggering mechanism of some case studies in Northern Italy, Landslides, 6, 241-251, 2009.

Montrasio, L., Valentino, R., and Quintavalla, C.: Estimation of the degree of saturation of shallow soils from satellite observations to model soil slips occurred in Emilia Romagna Region of Northern Italy, International Journal of Geosciences, 1, 58-65, 2010.

Moser, M. and Hohensinn, F.: Geotechnical aspects of soil slips in Alpine Regions, Eng. Geol., 19, 185-211, 1983.

Pieri, M. and Groppi, G.: Subsurface geological structure of the Po Plain, Progetto Finalizzato Geodinamica/Sottoprogetto "Modello Strutturale", Publ. Italian CNR, 1981.

Pistocchi, A., Bouraoui, F., and Bittelli, M.: A simplified parameterization of the monthly topsoil water budget, Water Resour. Res, 44, W12440, doi:10.1029/2007WR006603, 2008.

Qiu, C., Esaki, T., Xie, M., Mitani, Y., and Wang, C.: Spatiotemporal estimation of shallow landslide hazard triggered by rainfall using a three-dimensional model, Environ. Geol., 52, 1569-1579, 2007.

Salciarini, D., Godt, J. W., Savage, W. Z., Conversini, P., Baum, R. L., and Michael, J. A.: Modeling regional initiation of rainfallinduced shallow landslides in the eastern Umbria Region of central Italy, Landslides, 3, 181-194, 2006.
Salciarini, D., Godt, J. W., Savage, W. Z., Baum, R. L., and Conversini, P.: Modeling landslide recurrence in Seattle, Washington, USA, Eng. Geol., 102, 227-237, 2008.

Santacana, N., Baeza, B., Corominas, J., De Paz, A., and Marturia, J.: A GIS-based Multivariate statistical analysis for shallow landslide susceptibility mapping in La Pobla de Lillet area (Eastern Pyrenees, Spain), Nat. Hazards, 30, 281-295, 2003.

Sassa, K.: Recent urban landslide disasters in Japan and their mechanisms, in: Proceedings of 2nd International Conference on Environmental Management, 1, 47-58, 1998.

Saxton, K. and Lenz, A.: Antecedent retention indexes predict soil moisture, Journal of Hydraulic Division American Society of Civil Engineers, 93, 223-241, 1967.

Schmidt, J., Turek, G., Clark, M. P., Uddstrom, M., and Dymond, J. R.: Probabilistic forecasting of shallow, rainfall-triggered landslides using real-time numerical weather predictions, Nat. Hazards Earth Syst. Sci., 8, 349-357, doi:10.5194/nhess-8-3492008, 2008.

Simoni, S., Zanotti, F., Bertoldi, G., and Rigon, R.: Modelling the probability of occurrence of shallow landslides and channelized debris flows using GEOtop-FS, Hydrol. Process., 22(4), 532545, doi:10.1002/hyp.6886, 2008.

Terlien, M. T. J.: The determination of statistical and deterministic hydrological landslide-triggering thresholds, Environ. Geol., 35(2-3), 124-130, 1998.

Tiranti, D. and Rabuffetti, D.: Estimation of rainfall thresholds triggering shallow landslides for an operational warning system implementation, Landslides, 7(4), 471-481, 2010.

Valentino, R., Montrasio, L., Losi, G. L., and Bittelli, M.: An empirical model for the evaluation of the degree of saturation of shallow soils in relation to rainfalls, Can. Geotech. J., 48, 795809, 2011.

Vieira, B. C., Fernandes, N. F., and Filho, O. A.: Shallow landslide prediction in the Serra do Mar, São Paulo, Brazil, Nat. Hazards Earth Syst. Sci., 10, 1829-1837, doi:10.5194/nhess-101829-2010, 2010.

Wilson, R. C. and Wieczorek, G. F.: Rainfall thresholds for the initiation of debris flows at La Honda, California, Environmental and Engineering Geoscience, 1(1), 11-27, 1995.

Wu, W. and Sidle, R. C.: A distributed slope stability model for steep forested hillslopes, Water Resour. Res., 31(7), 2097-2110, 1995.

Zêzere, J. L., Trigo, R. M., Fragoso, M., Oliveira, S. C., and Garcia, R. A. C.: Rainfall-triggered landslides in the Lisbon region over 2006 and relationships with the North Atlantic Oscillation, Nat. Hazards Earth Syst. Sci., 8, 483-499, doi:10.5194/nhess-8-4832008, 2008.

Zhan, T. L. T., Ng, C. W. W., and Fredlund, D. G.: Field study of rainfall infiltration into a grassed unsaturated expansive soil slope, Can. Geotech. J., 44, 392-408, 2007.

Zhang, H. and Zhang, W. W.: Rainfall infiltration in cracked soil and its effect on slope stability analysis, in: Unsaturated Soils, Proc. of the 4th Asia Pacific Conference on Unsaturated Soils, edited by: Buzzi, O., Fityus, S., and Sheng, D., Newcastle, Australia, CRC Press, 313-318, 2009. 